\title{
The phylogeny and taxonomic status of the Chlorocystini (sensu stricto) (Homoptera, Tibicinidae)
}

\author{
A.J. de Boer \\ Institute for Systematics and Population Biology (Zoölogisch Museum), University of Amsterdam, P.O. \\ Box 94766, 1009 GT Amsterdam, The Netherlands
}

Keywords: Homoptera, Chlorocystini, Prasiini, phylogeny, taxonomy

\begin{abstract}
The "Baeturia and related genera complex", as defined earlier (De Boer, 1990) by shared aedeagal characters, is identified as the tribe Chlorocystini (sensu stricto). The Prasiini (sensu stricto) are identified as the sister group of the Chlorocystini (sensu stricto), while the genus $M u d a$ is recognized as the nearest outgroup. The phylogeny and biogeography of the sister group and outgroup is briefly discussed. Baeturia kuroiwae Matsumura is transferred to the genus Muda. A phylogenetic reconstruction of all 147 species of the Chlorocystini (sensu stricto) is presented, based on 154 characters and 409 character states. The computer program PAUP 3.1.1 (Swofford, 1993) was used for analysing the data; the genera Prasia and Muda were used as outgroups in this analysis. The results obtained from the computer analysis were slightly modified a posteriori, favouring some presumably phylogenetically important characters over strongly fluctuating ones. These final modifications were carried out with the aid of the computer program MacClade 3.0 (Maddison \& Maddison, 1992). A complete data matrix and a list of characters and character states are given in an appendix; for descriptions and illustrations of these characters one is referred to previous publications.
\end{abstract}

\section{Résumé}

Le "complexe de Baeturia et des genres apparentés", tel que précédemment défini sur la base de caractères aedéagaux partagés (De Boer, 1990), est ici identifié comme tribu Chlorocystini (sensu stricto). La tribu Prasiini (sensu stricto) est considérée comme groupe-frère des Chlorocystini (sensu stricto), tandis que le genre Muda est pris en qualité de plus proche "outgroup". Sont brièvement discutées la phylogénie et la biogéographie du groupe-frère et du "outgroup". L'espèce Baeturia kuroiwae Matsumura est transférée au genre Muda. Est proposée une reconstruction phylogénétique de l'ensemble des 147 espèces de Chlorocystini (sensu stricto), reconstruction basée sur 154 caractères et 409 "character states". Le programme d'ordinateur
PAUP 3.1.1 (Swofford, 1993) a été utilisé pour analyser les données; dans cette analyse les genres Prasia et Muda one été choisis comme "outgroups". Les résultats obtenus lors de cette analyse par ordinateur ont été légèrement modifiés a posteriori, pour favoriser certains caractères supposés phylogénétiquement importants, au dépens de caractères puissamment fluctuants. Ces modifications finales ont été réalisées à l'aide du programme d'ordinateur MacClade 3.0 (Maddison \& Maddison, 1992). Une matrice complète des données ainsi qu'une liste des caractères et des "character states" figurent dans un Appendix; on se rapporte à des publications précédentes pour la description et pour l'illustration de ces caractères.

\section{Introduction}

This paper presents a cladogram for the "Baeturia and related genera complex", a monophyletic group of tibicinid cicadas from the New Guineanwestern Pacific region. This group, here identified as the Chlorocystini (sensu stricto), was selected for area-cladistic study of an area comprising Maluku, New Guinea, and East-Melanesia. A well-solved cladogram is essential for such a study. The phylogenetic and biogeographic data of the genus complex and its presumed sister group, combined with such data of the Cosmopsaltriaria (a similarly distributed monophyletic group of cicadas) are used in an area cladistic analysis of New Guinea and adjacent areas of the Indo-Melanesian region (De Boer, 1995d). In that paper the area cladograms of these groups are related to the palaeogeographical data of the region.

The genus complex under study comprises 147 species, classified into 14 genera. Taxonomic revi- 
sions, with descriptions of the species, have been published in separate papers for most of these genera: Aedeastria De Boer, 1990 (De Boer, 1990; 1993a), Guineapsaltria De Boer, 1993 (De Boer, 1993b), Gymnotympana Stål, 1861 (De Boer, 1995a), Mirabilopsaltria De Boer, 1995 (De Boer, 1995b), Papuapsaltria De Boer, 1995 (De Boer, 1995c), Scottotympana De Boer, 1991 (De Boer, 1991), and Thaumastopsaltria Kirkaldy, 1900 (De Boer, 1992a). The large genus Baeturia Stảl, 1866 was subdivided into seven monophyletic species groups that were discussed in separate papers: the bloetei group (De Boer, 1989), conviva group (De Boer, 1986), exhausta group (De Boer, 1994a), guttulinervis group (De Boer, 1994b), loriae group (De Boer, 1994c), nasuta group (De Boer, 1982; 1994d), and viridis group (De Boer, 1992b); the Australian genera of the complex (Chlorocysta Westwood, 1851, Cystopsaltria Goding \& Froggatt, 1904, Cystosoma Westwood, 1842, Glaucopsaltria Goding \& Froggatt, 1904, Owra Ashton, 1912, and Venustria Goding \& Froggatt, 1904) will be treated in a single paper (De Boer, in prep.). For a discussion of the characters used in the present phylogenetic analysis one is referred to these taxonomic revisions.

In order to polarise the characters, two outgroups have been selected. These outgroups are discussed preceding the phylogenetic analysis proper. Some short remarks on their phylogeny and biogeography are made and some of the consequences of the presumed relationships between ingroup and outgroups for the traditional classifications are indicated.

\section{The existing classification of cicadas}

The higher classification of cicadas, as presented in the catalogues of Metcalf $(1963 a, b)$ and Duffels \& Van der Laan (1985) is mainly based on the work of Distant, performed roughly between 1888 and 1920. Many of the "divisions" proposed by Distant survive, virtually unchanged, as tribes in the modern classification. This classification thus predates phylogenetic systematics and the tribes thus formed are phenetic rather than phylogenetic groups. Nevertheless, though most of these tribes are presumably not monophyletic, most of the genera placed in any single tribe are probably closely related to each other, and the present classification into tribes can certainly form the basis for modern phylogenetic systematic work. The current subdivision of cicadas in six families (Cicadidae, Platypedidae, Plautillidae, Tettigadidae, Tettigarctidae, and Tibicinidae) is even more disputed than the classification in tribes, although the two largest families, the Cicadidae and the Tibicinidae, and the small family Tettigarctidae are generally considered to be sound groups (see Duffels, 1993).

Several tibicinid genera from New Guinea and Eastern Australia were recognized to form one monophyletic group, based on apomorphous aedeagal characters (De Boer, 1990). This group, of which the genera were previously placed in four different tribes (viz., the Chlorocystini, Gymnotympanini, Hemidictyini, and Taphurini), was not given the official status of tribe or subtribe, since its sister-group relationships were not known. Pending the discovery of its sister group, the group was given the preliminary name of "Baeturia and related genera complex."

\section{A quest for the sister group of the "Baeturia and related genera complex"}

The species of the "Baeturia and related genera complex" possess, apart from their apomorphous aedeagal shape, one character which separates them from the vast majority of other tibicinid cicadas: they lack a medial uncus lobe. The presence of a distinct and posteriorly directed medial uncus lobe, often larger than either the lateral uncus lobes or the claspers, is found throughout the cicadas, both in the Cicadidae and in the Tibicinidae. This character is very unstable within the Cicadidae since presence and absence often occur among closely related taxa, but it can possibly be regarded plesiomorphous in the Tibicinidae where a total absence occurs less frequently. The mere size of this lobe varies strongly within both families, which makes it questionable whether the lobes as found in these families all have a monophyletic origin.

The "Baeturia and related genera complex" 
shares the absence of a medial uncus lobe with the Southeast Asian genera Muda Distant, 1897 and Kumanga Distant, 1905, while this lobe is either absent or strongly reduced in size in the oriental Prasiini (consisting of the genera Arfaka Distant, 1905, Jacatra Distant, 1905, Lembeja Distant, 1892, and Prasia Stảl, 1863, see De Jong, 1985). Tibicinid species without a distinct medial uncus lobe can also be found in several geographically farther removed genera, for example Fractuosella Boulard, 1979, Abroma Stảl, 1866 (Boulard, 1979), and Dinarobia Mamet, 1957 (Orian, 1954) from the Mascarene Isles, Abricta Stål, 1866 (Orian, 1964) from Australia, and the African genera Trismarcha Karsch, 1891 (Dlabola, 1960) and Lamotialna Boulard, 1975 (Boulard, 1976) all lack a distinct medial uncus lobe. This list does not pretend to be complete; it was based on comparison of genital drawings of a selection of the more recent literature.

Taking into account the above-discussed instability of the character, it is far from certain that the shared absence of a medial uncus lobe forms a synapomorphy for all the genera lacking that lobe and a thorough phylogenetic revision of the higher taxa of cicadas is needed to come to any definite conclusions. However, it is supposed here that the immediate relatives of the "Baeturia and related genera complex" must be looked for among the taxa lacking a distinct medial uncus lobe. Based on the absence of a distinct medial uncus lobe (1 in Fig. 1a) the above-listed genera might well form (part of) a monophyletic group.

The oriental Prasiini are the most likely candidate to be the sister group of the "Baeturia and related genera complex". Apart from the reduced or absent medial uncus lobe, the species of that taxon share several characters that also occur in several species of the "Baeturia and related genera complex" and represent possible apomorphies: a very narrow hyaline border along the hind margin of the tegmen, a medially furrowed pronotum, a continuous lateral ridge on the pronotum (only in Prasia), a very narrow cruciform elevation on the mesonotum, a strongly bent proximal spine on the fore femur (only in Arfaka and part of Lembeja and Prasia), and a ventrally angularly swollen postclypeus. These characters are but rarely encoun- tered in other groups of cicadas. The first five characters might all be apomorphies for the "Baeturia and related genera complex" and the Prasiini together (4-8 in Fig. 1a), but then each of the characters must have reversed several times in these two groups. The angularly swollen postclypeus is also found in Muda. One character in particular, viz., the very narrow cruciform elevation on the mesonotum, strongly suggests a close relationship between the oriental Prasiini and the "Baeturia and related genera complex". That remarkable feature is shared by the Prasiini and the genera Cystopsaltria and Cystosoma. The distributions of the above-discussed characters are regarded to be convincing enough to propose the oriental Prasiini as the sister group of the "Baeturia and related genera complex", provided that complex is monophyletic. Some of these characters could also indicate that the oriental Prasiini are to be included in the "Baeturia and related genera complex" and that the latter [exclusively] is not monophyletic. This problem can only be tackled by a phylogenetic analysis that includes the nearest outgroups, and these are at present not known with any certainty. For now the unique aedeagal shape of the "Baetur$i a$ and related genera complex" is regarded as sufficient evidence for the monophyly of that group ( 9 in Fig. 1a).

It is supposed that Muda, based on its postclypeus shape ( 2 in Fig. 1a), forms the sister group of the oriental Prasiini and the "Baeturia and related genera complex" combined. Several characters of Muda, however, indicate a relationship with the oriental Prasiini. The large and inwardly curved lateral lobes of the male pygofer of Muda are presumably homologous with similar, but posteriorly directed, lobes in the Prasiini, while the extremely long ovipositor, which is found in Muda, Jacatra, and Lembeja, also might indicate a relationship between $M u d a$ and the Prasiini. This latter character is not considered a strong synapomorphy, since it occurs in many other cicadas. Based on the pygofer lobe (1 in Fig. 1b), Muda and the Prasini might be sister groups, otherwise this lobe must be synapomorphous for Muda, the Prasiini, and the "Baeturia and related genera complex" together (3 in Fig. 1a) and must then have reversed in the latter group. 
a

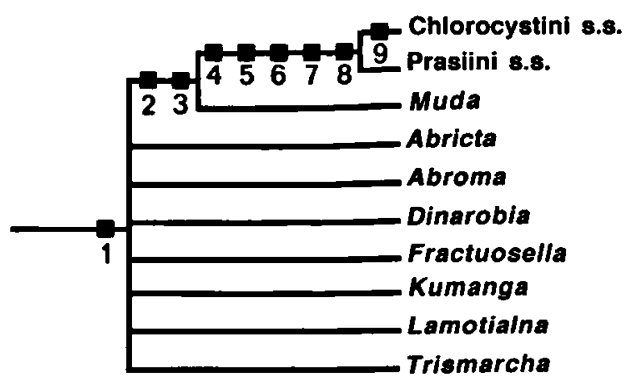

b

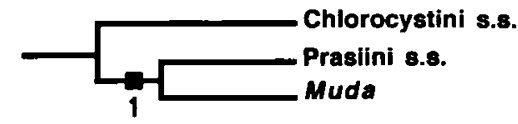

Fig. 1. (a), Cladogram showing the possible relationships of the Chlorocystini (sensu stricto). (b), Alternative cladogram of the possible relationships of the Chlorocystini (sensu stricto) with Muda and the Prasiini as sister groups. Numbers refer to characters discussed in the text.

The Southeast Asian genus Kumanga and some of the above-listed genera lacking a medial uncus lobe and included in the polytomy of Fig. 1a might possibly have to be included in the sister group of the Prasiini and the "Baeturia and related genera complex" combined.

In a tentative cladogram of the Mauritian cicadas, Boulard (1990) does not recognize the relationship between the genera of the "Baeturia and related genera complex" (viz., the tribes Chlorocystini and Gymnotympanini, see below) and the oriental Prasiini (the latter do not occur on Mauritius and are not included in the cladogram anyway), but he does indicate the genera Abricta and Abroma as belonging to the possible sister group. The phylogenetic reasoning behind his cladogram remains obscure.

Tribal allocation of the "Baeturia and related genera complex"

The "Baeturia and related genera complex" comprises 14 genera: Aedeastria De Boer, Baeturia Stål, Chlorocysta Westwood, Cystopsaltria Goding \& Froggatt, Cystosoma Westwood, Glaucopsaltria Goding \& Froggatt, Guineapsaltria De Boer, Gymnotympana Stål, Mirabilopsaltria De Boer, Owra Ashton, Papuapsaltria De Boer, Scottotympana De Boer, Thaumastopsaltria Kirkaldy, and Venustria
Goding \& Froggatt. Most of these genera, viz. those of which the descriptions predate that of the "Baeturia and related genera complex", are either included in the tribe Chlorocystini (Chlorocysta, Glaucopsaltria, Owra, Thaumastopsaltria, and, recently transferred from the Taphurini by Moulds (1990), Venustria), or in the Gymnotympanini (Baeturia and Gymnotympana). The tribe Gymnotympanini was separated from the Chlorocystini by Boulard (1979), though he regards these tribes as sister groups (Boulard, 1990). Cystosoma is included in the Hemidictyini and Cystopsaltria was recently transferred from the Chlorocystini to that same tribe (Moulds, 1990).

The presumed monophyletic "Baeturia and related genera complex" should be included in the tribe Chlorocystini since the complex contains the type genus, Chlorocysta, of that tribe. In this construction the Gymnotympanini must be regarded as a junior synonym of the Chlorocystini, since the type genus of the Gymnotympanini (Gymnotympana) also belong to the "Baeturia and related genera complex" and therefore to the Chlorocystini in their new concept. This also implies that Cystosoma and Cystopsaltria must be transferred from the Hemidictyini to the Chlorocystini.

\section{The Chlorocystini}

The Chlorocystini (sensu lato) do not form a monophyletic group in the new concept proposed here; the 14 genera of the "Baeturia and related genera complex" (the Chlorocystini sensu stricto) are more closely related to the oriental Prasiini than to the remaining genera included in the tribe. These remaining genera of the Chlorocystini, 15 in number, will have to be removed to other tribes. Six of these genera (Akamba Distant, 1905, Bavea Distant, 1905, Decebalus Distant, 1920, Musoda Karsch, 1890, Nablistes Karsch, 1891, and Stagira Stål, 1861) occur in Africa, two (Fractuosella and Dinarobia) are endemic to Mauritius and Réunion, two (Muda and Kumanga) come from Southeast Asia, one (Toxopeusella Schmidt, 1926) is restricted to Buru Island in Maluku, New Guinea, the Bismarck Archipelago, and the Solomon Islands, and 
two (Conibosa Distant, 1905 and Durangona Distant, 1911) are endemic to Middle and South America, respectively.

As explained above, the genus Muda alone might be the sister group of the Chlorocystini (sensu stricto) and the Prasiini (sensu stricto) together (Fig. 1a), but Dinarobia, Fractuosella and Kumanga might be part of that sister group, or be closely related to that sister group.

Several of the African genera have been recently treated in literature. Bavea, Musoda, and Stagira share a large tube-like medial uncus lobe (Boulard, 1979; Villet, 1993). They are supposed to be related to the South African genera Xosopsaltria Kirkaldy, 1904 and Tettigomia Amyot \& Serville, 1843, and should possibly be included in the mainly African tribe Tettigomyiini. Nablistes likewise has a very large medial uncus lobe (Dlabola, 1958) and is presumably also more closely related to the Tettigomyiini. No genital drawings have been published for Akamba.

Conibosa is reported to share the total absence of opercula with the South American genera Coata Distant, 1906 and Prunasis Stål, 1862 (Boulard, 1979). Coata and Prunasis are at present placed in two different families: Coata belongs to the Tettigadidae and Prunasis to the tribe Parnisini of the Tibicinidae. The correct tribal allocation of Conibosa is therefore uncertain. No recent literature is available on Durangona, but Distant states in its first description that the genus is allied to Conibosa.

Toxopeusella presumably belongs to the tribe Cicadettini (De Boer, 1990). Its species share the typical trifid aedeagus and a reddish costal area of the tegmen with the genera of that tribe (see Boulard, 1981a).

\section{The Prasiini}

The Prasiini (sensu lato) are likewise not monophyletic. The four oriental genera (the oriental Prasiini or the Prasiini sensu stricto) are more closely related to the Chlorocystini (sensu stricto) and to the genus Muda than to the three other genera of the tribe. Two of these other genera (Lacetas
Karsch, 1890 and Iruana Distant, 1905) are African, and one (Sapantanga Distant, 1905) comes from South America. These non-oriental genera were placed in the Prasiini because of their narrow head and protruding postclypeus. However, closer examination shows that there are large differences between these and the oriental genera. The oriental Prasiini have a much narrower head than either Lacetas, Iruana, or Sapantanga. Furthermore, the postclypeus of these latter three genera is not angularly swollen as is the case in the oriental Prasiini; Lacetas and Sapantanga have a conically protruding postclypeus, while Iruana has a much smaller, hardly swollen, postclypeus. Iruana (Dlabola, 1960; Boulard, 1981b, 1990) and Lacetas (Boulard, 1975a, 1975b) have a very distinct medial uncus lobe. Lacetas is presumably related to Hovana Distant, 1905 and Hemidictya Burmeister, 1835, sharing a very similar streamlined head and thorax (De Boer, in prep.) and should probably be placed in the tribe Hemidictyini. Only two females of Sapantan$g a$ were examined. That genus is presumed to be related to the South American genera Prosotettix Jacobi, 1907 and Selymbria Stål, 1861 of the Taphurini (De Jong, pers. comm.).

\section{Phylogeny and biogeography of the outgroups}

The Prasiini (sensu stricto), the supposed sister group of the Chlorocystini (sensu stricto), and the genus Muda serve as outgroups in the phylogenetic analysis of the Chlorocystini. In this section some of the most characteristic features and possible apomorphies of the various genera of these outgroups are discussed in relation to a tentative cladogram of the Prasiini. Furthermore, some remarks on the geographical distributions of these genera will be made.

\section{The Prasiini (sensu stricto)}

Thanks to the revisionary work of De Jong (1982, $1985,1986,1987)$ and De Jong \& Duffels (1981) the oriental Prasiini form a fairly well-known group. Regrettably the revision of this tribe has not been 


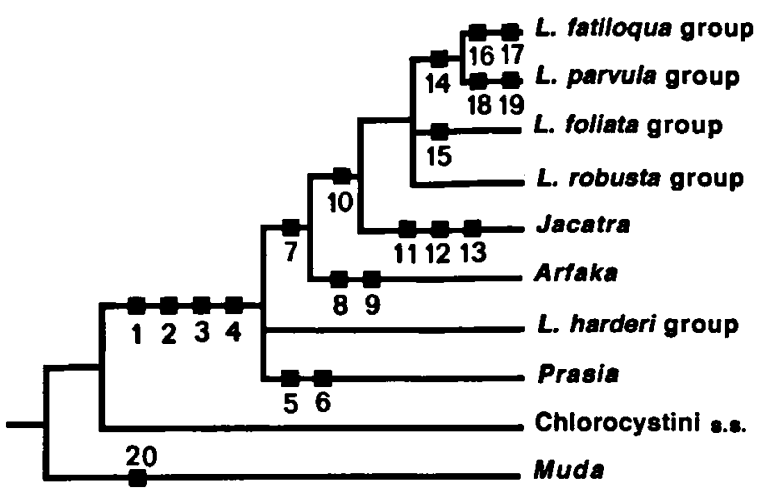

Fig. 2. Tentative cladogram of the Prasini (L. = Lembeja). Numbers refer to characters discussed in the text.

completed and a fully solved phylogenetic reconstruction is not available. The following remarks about the phylogeny and the biogeography of the oriental Prasiini are principally based on De Jong's publications and on unpublished observations made by the same author. A tentative cladogram of the Prasiini is presented in Fig. 2.

The oriental Prasiini form a supposedly monophyletic group, containing the genera Arfaka, Jacatra, Lembeja, and Prasia (De Jong, 1985), on the basis of the following presumed apomorphies: (1) a very narrow vertex, with the ocelli close together; (2) a large obconical and triangularly protruding postclypeus; (3) a very narrow hyaline border along the hind margin of the wing; and (4) well-developed and posteriorly projecting protuberances on the lateral lobes of the male pygofer (1-4 in Fig. 2). The latter character is presumably homologous with similarly shaped, though incurving, lobes in Muda.

Other characters, that either have a very limited distribution outside the oriental Prasiini (a very narrow cruciform elevation on the mesonotum), or are not shared by all members of the group ( $\mathrm{a} \mathrm{fu}$ sion of wing veins $\mathrm{Cu} 2$ and A 1 , a dorsal aedeagal appendage) also seem to support a close relationship between the species of the oriental Prasiini. The oriental Prasiini are distributed in Sumatra, Java, Borneo, the Lesser Sunda Islands, Philippines, New Guinea, and northern Queensland, but have most species on Sulawesi.

The genus Prasia contains seven species, restrict- ed to Sulawesi and the nearby island of Muna. According to De Jong (1985) the monophyly of Prasia is based on a single apomorphy: "the degrading lateral margin of the male pygofer between the lateral lobes and the caudodorsal beak" ( 5 in Fig. 2). In addition to this, a long and spine-shaped male caudodorsal beak is presumed here to be apomorphous for the genus as well (6 in Fig. 2). Other apomorphies for Prasia can possibly be found in the shape of the lateral lobes of the pygofer and in the structure of the base of the aedeagal appendages. Prasia is easily separated from the other Prasiini by a sharply edged lateral margin of the pronotum. This character is also found in Cystosoma, Cystopsaltria, three species of Mirabilopsaltria, and three species of Gymnotympana. It is assumed that Prasia forms the sister group of Arfaka, Jacatra, and Lembeja combined. The latter three genera share a carinated male abdomen as a presumed synapomorphy (7 in Fig. 2).

Arfaka is a small genus with only 3 species, of which one is still undescribed. The genus is presumably endemic to Cendrawasih (the Vogelkop Peninsula of New Guinea) and the adjacent islands of Waigeu and Salawati. Arfaka is easily recognized by the long and slender apical areas of the tegmina and wings, a large laminiform protuberance on the lateral lobes of the pygofer, and a peculiar narrow and bilobate aedeagal apex. The first character also occurs in several genera of the Chlorocystini; the latter two characters presumably represent good apomorphies for this genus (8 \& 9 in Fig. 2). Arfaka presumably forms a monophyletic group with Jacatra and Lembeja, but its phylogenetic relationships are not unambiguous. Arfaka and Prasia share a sexual dimorphism in the anal areas of the wings and might be sister groups, together forming the sister group of Jacatra and Lembeja together. A similar sexual dimorphism was found in Gymnotympana (De Boer, 1995a) and the Baeturia loriae group (De Boer, 1994c) and therefore the character cannot be regarded a strong synapomorphy. Jacatra and Lembeja share an elongate first tergite in male individuals as a presumed synapomorphy (10 in Fig. 2).

Jacatra contains only 2 species, occurring in Java and Sumatra. Only one species is described. The 
genus can be recognized by three apomorphies: an aberrant vein partly dividing the 4th ulnar area of the tegmen, a proximally weakly tridentate first tergite in males, and a peculiar coalescence of the apical lobes of the aedeagus (characters 11-13 in Fig. 2).

Lembeja, with about 40 species, forms by far the largest genus of the oriental Prasiini. Five monophyletic species groups can be recognized within Lembeja, and three such groups have been revised: (1) the foliata group, with 13 species endemic to Sulawesi and Sangihe Island, can be recognized by a longitudinal ridge on the first sternite of males (15 in Fig. 2) (De Jong, 1986); (2) the fatiloqua group with 10 species, most of which are endemic to Sulawesi, also occurs in Mindanao, northern Borneo, Sumba, southeastern New Guinea and northern Queensland, and has a strongly developed medial dent in the first tergite of males and an inflatable telescoping male abdomen as its presumed apomorphies (16-17 in Fig. 2) (De Jong, 1987); and (3) the small parvula group with 2 species endemic to Sulawesi has a hindwards directed distal margin of the male pygofer and five apical areas in the wing as apomorphies (18-19 in Fig. 2) (De Jong, 1987). Two other groups, the harderi group from the Lesser Sunda Islands and the robusta group from New Guinea, Obi Island, and northern Queensland, can be recognized (De Jong, pers. comm.), but these groups still await description.

The phylogeny of Lembeja is not resolved, but the genus is assumed to be non-monophyletic in its present concept. Lembeja harderi Schmidt, 1925 and several related, undescribed, species forming the harderi group, are probably more closely related to Prasia and Arfaka than to other species of Lembeja. These species lack the carinated male abdomen and elongate first tergite of males, common to the other Lembeja species, and share a fairly small tymbal and sexual dimorphism in wings with Prasia and Arfaka. The four remaining species groups of Lembeja together are thought to form a monophyletic group (De Jong, pers. comm.), although no synapomorphous character has as yet been published. The fatiloqua and parvula groups are supposedly sister groups, with a medial indenta- tion of the first tergite of the male as presumed synapomorphy (14 in Fig. 2).

\section{The genus Muda}

Muda presently contains three species, but several new species can presumably be separated from these. Muda kuroiwae (Matsumura, 1913) n. comb. from the Ryukyu and Loochoo Islands of southern Japan, is hereby transferred from Baeturia to Muda. Both other species are distributed over the Greater Sunda Islands (Java, Sumatra, and Borneo), and the Malay Peninsula. Muda is easily recognized by its peculiar pygofer, being sharply folded along its dorsal margin and, in consequence, nearly triangular in cross section (20 in Fig. 2). The large and rounded laminiform protuberances on the lateral lobes of the pygofer, which are probably homologous with the large protuberances in the Prasiini (sensu stricto), curve or fold mesiad along the base of the anal valves so that their apices are adjacent. These lobes possibly replace the strongly reduced claspers in function. Muda shares a somewhat similarly shaped postclypeus with the oriental Prasiini, and with Cystopsaltria, Cystosoma, and Thaumastopsaltria.

\section{The phylogenetic analysis}

Phylogeny and parsimony, the value and restrictions of a computer analysis

The method of phylogenetic reconstruction, as developed by Hennig $(1950 ; 1966)$, is based on the assumption that if a character state is uniquely shared by two species, that character state did not evolve independently in these two species, but developed only once in the common ancestor of those species. Based on this principle, dichotomous family trees or cladograms can be constructed, in which all the various groupings of species which share a direct common ancestor (monophyletic groups) are supported by one or more shared, but otherwise unique, character states that developed in that common ancestor.

This may sound very simple in theory, but in 
practice one immediately runs into trouble when character state distributions conflict. Suppose that a species "A" shares one character uniquely with species " $B$ " and two characters uniquely with species " $C$ ". In that case the most parsimonious solution is chosen as the most likely.

The principle of parsimony is nothing but applying Ockham's razor, choosing for the simplest solution in view of all the facts. Translated to phylogenetic analysis, this means that the shortest cladogram is opted for, the cladogram requiring the smallest number of character changes that still is compatible with the data set. In our example, a relationship between " $A$ " and " $C$ " is favoured since in that option only one character need be supposed to have developed twice.

If we accept evolution as being a parsimonious process, a statement that is by no means proven, then it is clear that the "true" cladogram of the evolutionary relationships between species of a group is also the most parsimonious one. Regrettably the reversal of this statement, that the most parsimonious cladogram is also the "true" cladogram, is not necessarily true, perhaps even unlikely. The reason is that any given data set is per definition incomplete. In the present study of cicadas, for example, only morphological characters are used, but song, periodicity, food preference, ecological constraints, and even distribution are all characters of the species. Furthermore, of these morphological characters, only characters of adults were used, as represented by a sometimes very limited number of specimens, and only those characters were used that were recognized as such by the author. In short, the data set contains only a fraction of the total number of characters and that fraction is far from randomly chosen.

Apart from being incomplete, the data set is bound to be inaccurate as well. Many of the homoplasous characters (character states that appear to develop two or more times in the cladogram) that were recognized, and therefore scored, as one and the same character (state) are in fact two or more character(state)s. Often this cannot be recognized a priori, it can only be deduced a posteriori. Consider for example the number of sclerotized ridges on the tymbal of cicadas. If a spe- cies has six ridges, and provided that this number is not the most plesiomorphous state, it could have acquired that number by gaining a sixth or loosing a seventh ridge. If it gained a ridge, this can have happened by the duplication of any of its previous five ridges; if it lost a ridge, this can be due to the loss of any of its previous seven ridges, or to the fusion of any two successive ridges. In short, if any two species share the same number of tymbal ridges, unless these species are closely related, it is unlikely that a shared number of ridges represents a homology. The character "number of tymbal ridges" should therefore only be allowed to play a role within species groups and should be entirely disregarded at a more basal level. Presumably there are many more of these types of characters; they can often be recognized a posteriori by a low consistency index.

Another consideration should be that one character simply does not equal another. While, in genetic terms, the substitution of one base-pair might be sufficient to change one character from a state " $A$ " to a state " $B$ " and back, a much more drastic change in the DNA structure might be required to change another character from state "A" to state "B". One change in the latter character might (in evolutionary sense) be less parsimonious than five changes, gains and losses, in the former. Such character differences cannot be recognized a priori, though an education guess can be made that the more complex structures and many genital characters and characters responsible for the mutual recognition between the sexes belong to the latter type. Characters of the former, easily changing, type can be recognized a posteriori by a low consistency index, but there is no way of telling how many changes in one character equal a change in another. Even when possible differences in genetic complexity are not made apparent by differences in consistency index, characters with an obvious function in reproduction (as clasper and aedeagal characters) must presumably prevail over characters with an obscure function (as a pointed or truncate caudodorsal beak on the pygofer). However, we must be reluctant in this, since if we do not know the function, this does not mean that there is no function. Still, the former characters are likely to 
have been more subjected to natural selection than the latter.

The computer program PAUP 3.1.1 (Swofford, 1993) offers many options to adjust the data set a priori, in order to counteract some of the abovediscussed problems. Characters can be ordered, or made irreversible, or given a weight (for explanations see the manual of the program), but, since there is, at least in morphological studies as the present one, no objective method to determine what character should be adjusted in what way, it is feared that such manipulations are only performed to bring the computer results closer to the pre-conceived ideas of the scientist. Alternatively, PAUP gives the opportunity to weight characters a posteriori, with a character weight relative to the consistency index or retention index of that character (Farris' reweighting method; Farris, 1969). However, then the weights given are dependent on the behaviour of a character in a cladogram that was unsatisfactory to us in the first place. In large data sets as the one presented here, such a successive weighting runs the risk of loosing valuable information. When a character supports a sound monophyletic group in one part of the cladogram but is highly inconsistent in other parts, it will have a low consistency index and thus will get a low weight, as a result of which we might lose the support for the monophyletic group. Such a group should then be protected by a constraint before reweighting.

Ockham's razor is used in philosophy to decide between questions where there are no convincing arguments in favour of any one solution. The simplest solution is chosen by lack of good arguments pro or contra. I plea for a similar use of parsimony in phylogenetic analysis. A monophyletic group is recognized in principle by one or more apomorphous characters, characters that developed in the common ancestor and are inherited by the descendants. Of course, a common ancestor could have developed an apomorphy that changed or reversed in some, or many, of its descendants, as a result of which the monophyletic group cannot easily be recognized as such. The monophyly, though existing in reality, is then apparently not supported by shared characters and, unless we know exactly how the apomorphous character changed in the descendants, we have no convincing arguments to regard that group as monophyletic. On the other hand, if we do recognize groups of species that share a unique character, we do have a strong argument to regard that group as monophyletic. In that case, unless this group contradicts with other equally well-argued monophyletic groups, there is no need for the parsimony criterion, nor for computer analysis. One should not allow to let the computer compute what is already known. The computer could come up with a more parsimonious solution based on characters, none of which are distinctive for the monophyletic groups they are supposed to support. Only when the scientist does not have any strong arguments in the form of shared apomorphous characters in favour of certain groupings, the most parsimonious solution is the best he can come up with. When a character is regarded as apomorphous for a certain species group by argument of its exclusivity and considered important in view of its supposed genetic complexity, and/or its supposed role in sexual isolation, and that character does not conflict with another equally well-argued possible apomorphy, then the final cladogram should show the species group in question as monophyletic, notwithstanding any conflict with characters of supposed minor importance. When there are such strong arguments in favour of a certain decision, there is no need for parsimony. Only when no clearly apomorphous characters can be found, or when two equally well-supported apomorphies contradict, parsimony offers a last resource and the most parsimonious solution should be chosen as the most likely one.

Although the relative importance of characters can often be made plausible, there is, at least in morphological studies, no way of quantifying that importance and we therefore have to accept that the science of phylogeny will always contain an element of subjectivity.

A computer analysis as discussed below has no other objective than to demonstrate the amount of conflict between the supposed apomorphies and the remaining characters. The amount of consistency between the computer tree and a tree solely based 
on the supposed apomorphies can be taken as a kind of measure for the soundness of these apomorphies. Only when the computer tree deviates strongly from the tree based on the recognized apomorphies, the value of these apomorphies must be seriously reconsidered. Since these deviations are not easily quantified, it must be left to the scientist to decide what deviations are acceptable.

\section{The computer analysis}

Material. - A cladistic analysis was performed for the 147 species of the Chlorocystini (sensu stricto), using 154 characters with a total of 409 character states.

Characters. - All characters are introduced as unordered and no character weights have been applied for reasons discussed above, that is: all characters have an equal weight. A matrix of the data and a list of the characters are included in an Appendix.

Outgroups. - The character states as found in Prasia and Muda are added to the data matrix, as representing the presumed outgroup states. These two genera were defined as outgroup in the search. Prasia, as representing the sister group Prasini, was chosen for several reasons: (1) Prasia is presumably the most basal genus of the oriental Prasiini (see Fig. 2), (2) a taxonomic revision of Prasia with genital drawings is available, (3) of all Prasiini, Prasia shows the greatest similarity to the species of the Chlorocystini (sensu stricto), and has therefore presumably retained more of the plesiomorphous states, but an analysis with a third outgroup is necessary to check this point.

Constraints. - Two topological constraints were built in. The male genitalia (which comprise $47 \%$ of the characters used) of the genus $M u d a$ are so completely different from those of the Prasiini and the Chlorocystini that the remaining characters of that genus carry insufficient weight to force $M u d a$ to an outgroup position within the tree. If a third outgroup were known, this problem would probably not exist. The problem was solved by putting a topological constraint on the monophyly of the Chlorocystini.

A second constraint, on the monophyly of a group containing the genera Baeturia, Chlorocysta, Glaucopsaltria, Guineapsaltria, Gymnotympana, Owra, Papuapsaltria, Scottotympana, and Venustria, appeared necessary to force some single and deviating species into their correct genus. Although a definite segregation, based on several presumed apomorphies (see Fig. 4), appears to exist between the above nine genera and the remaining five genera of the Chlorocystini, some deviations occur in both these subgroups which had a negative effect on the whole tree.

The search. - An heuristic search was made (in view of the size of the data set) with the options random adding sequence by stepwise addition, holding one tree at each step, keeping minimal trees only and collapsing zero length branches, and the option Mulpars off. Swapping was performed on minimal trees only with the swapping algorithm tree bisection - reconnection. The trees found had a length of 875 steps; these were used as starting trees in a new search, now with the option Mulpars on, and a set maximum of 600 equally parsimonious trees was reached.

Results. - The strict consensus tree of these $\mathbf{6 0 0}$ trees is given to a generic or species group level in Fig. 3. The total strict consensus tree has a length of 821 steps; consistency index $=0.29$; retention index $=0.82$; rescaled consistency index $=0.24$. The $50 \%$ majority rule consensus tree is one of the 600 trees with a length of 875 steps; consistency index $=0.27$; retention index $=0.80$; rescaled consistency index $=0.22$. This tree shows nearly all previously recognized genera and species groups as monophyletic groups. Parts of this $50 \%$ majority rule consensus tree are given in Figs. 5, 6, 7, 9, 12a, and 13. In other parts this tree is identical to the one presented in Fig. 4. Several of the 600 trees found give a most interesting alternative for the phylogeny of the genus Papuapsaltria (see Fig. 12b).

Modifications. - The strict, and 50\% majority rule consensus trees differ in several instances from 


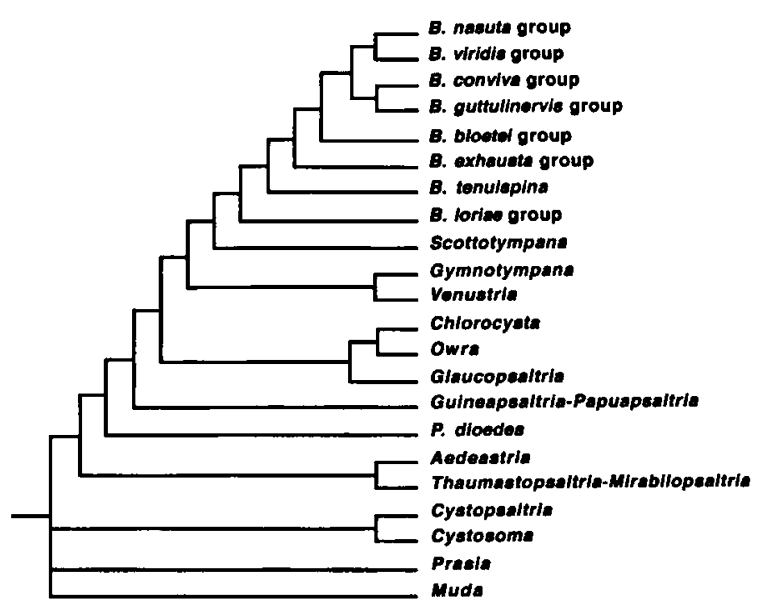

Fig. 3. Simplified version of the Paup reconstruction for the Chlorocvstini s. s. (strict consensus) $(B .=$ Baeturia; $P$. $=$ Papuapsaltria).

the tentative cladograms published earlier (De Boer, 1994a, d; 1995a, b, c). These differences are discussed below and some minor modifications are made. The "costs" of each of these modifications and of some proposed alternatives, expressed in the number of extra steps needed to construct the tree, were calculated with the computer program MacClade 3.0 (Maddison \& Maddison, 1992). To ensure that the most parsimonious tree that takes the required modifications into account was reached, a new run was made in PAUP, but now using a constraint tree enforcing the proposed changes. The resulting alternative shortest acceptable tree is shown in Fig. 4. This tree has a length of 906 steps. Where several equally parsimonious solutions were possible, the tree of Fig. 4 was made to resemble the $50 \%$ majority rule consensus tree as much as possible. Modified in the same way, a tree with the alternative phylogeny for Papuapsaltria yields a shortest acceptable tree of 905 steps (cf. Figs. 12c and 14).

The black squares in Fig. 4 indicate one or more characters that are considered phylogenetically meaningful; these are given in Appendix 2 . Branches without a black square just represent the most parsimonious way to deal with all characters concerned.

The phylogenies and positions of the various spe- cies groups and genera will be discussed from left to right (Fig. 4), starting with the genus Baeturia.

\section{Discussion of modifications}

\section{Baeturia}

The ingroup phylogeny of the Baeturia nasuta group is very uncertain, due to a lack of distinct apomorphies, which is illustrated by the fact that this group appears as a single polytomy in the strict consensus tree. The $50 \%$ majority rule tree of this group (Fig. 5) differs from the tentative cladogram published earlier (De Boer, 1994d) in that B. marmorata and not $B$. guttulipennis is placed at the base of the group. The nasuta group minus $B$. guttulipennis was considered monophyletic based on two apomorphies: a narrowly protruding postclypeus and four tymbal ridges. A transparent abdomen is apomorphous for the nasuta group, and the untransparent abdomen of $B$. marmorata, which is responsible for the basal position of that species, was considered a character reversal. The apomorphy of four tymbal ridges was not recognized in the present analysis, caused by the fact that all characters were introduced as unordered (though the number of ridges reduces within Baeturia from 7-8 to 4 ridges; the number of ridges can increase in other genera). Removing $B$. guttulipennis to the base of the nasuta group, as proposed here, costs 1 extra step (Fig. 4). The phylogeny of the monophyletic subgroup of arabuensis, bipunctata, gibberosa, laminifer, mamillata, and retracta agrees with the cladogram published earlier.

The phylogeny of the viridis, conviva, and guttulinervis groups, and their relative positions, agree with the cladograms published earlier (Duffels \& De Boer, 1990; De Boer, 1994a, d). Their phylogeny as given in Fig. 4 is identical to that of the $50 \%$ majority rule tree and, for the conviva and guttulinervis groups, to the strict consensus tree.

The differences between the species of the bloetei group are often very small, which has resulted in an only partly resolved cladogram, with several polytomies. Even this cladogram should be considered as doubtful. Only the monophyly of the Moluccan 


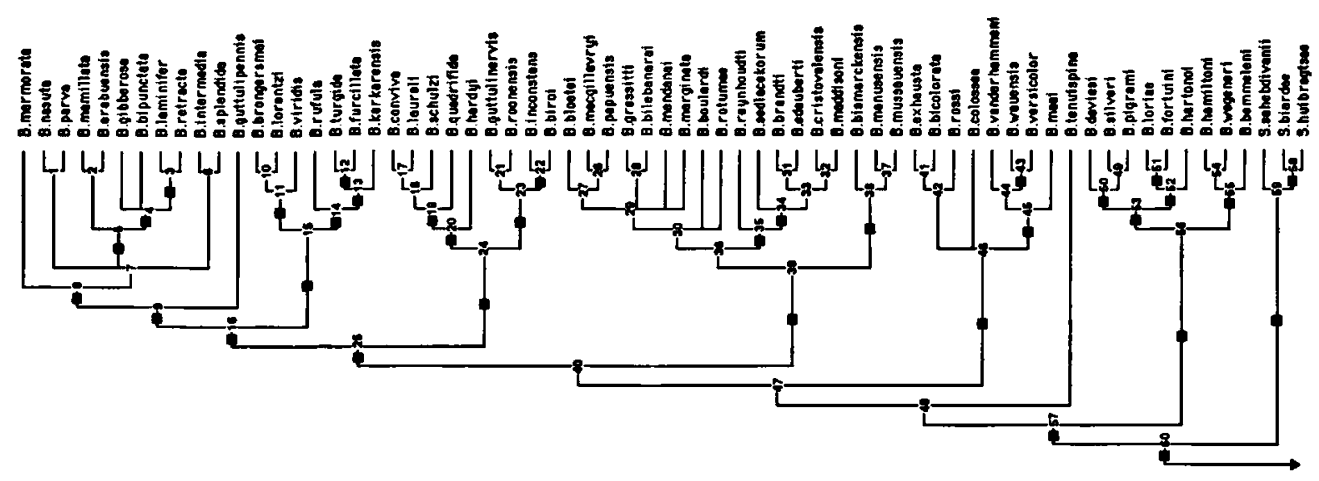

Fig. 4. Most parsimonious McClade reconstruction for the Chlorocystini s. s. after including the modifications suggested. Tree length $=906$; consistency index $=0.26$; retention index $=0.79$; rescaled consistency index $=0.21$. Black squares refer to the apomorphies listed in Appendix 2.

and New Guinean species $B$. macgillavryi, $B$. bloetei, and $B$. papuensis and of the east Melanesian species $B$. brandti, $B$. cristovalensis, $B$. edauber$t i, B$. maddisoni, $B$. reynhoudti, and $B$. sedlacekorum are assumed to be sound (Fig. 6). The latter group does not appear in the strict consensus tree, however. The species from the Bismarck Islands ( $B$. bismarckensis, B. manusensis, B. mussauensis), which were presumed to be monophyletic, based on a shared aedeagal shape, and closely related to $B$. papuensis (cf. De Boer, 1989), appears as paraphyletic at the base of the bloetei group in the $50 \%$ majority rule tree (Fig. 6). Joining these three species to a monophyletic group, as proposed here, costs 1 extra step (Fig. 4). B. papuensis should possibly be included in this group. The suggested monophyly of the species of the bloetei group excluding these Bismarck species is based on a shared broad aedeagal pore. The aedeagus of the Bismarck species is quite different in aspect from that of other Baeturia species. The narrow pore of the Bismarck species might well be a reversal, and the basal position of this subgroup within the bloetei group is regarded far from certain.

The phylogenetic reconstruction of the exhausta group presented in Fig. 4 closely matches the presumed relationships as discussed earlier (De Boer, 1994a). This phylogenetic reconstruction is identical to that of the strict consensus tree.

In an earlier discussion on the phylogeny of the loriae group, a subdivision into two monophyletic subgroups was suggested (De Boer, 1994c). $B$. daviesi, B. fortuini, B. hartonoi, B. loriae, B. pigra$m i$, and $B$. silveri were supposed to torm a monophyletic group based on a shared clasper protuberance. The position of B. tenuispina, as part of either the exhausta group or of the loriae group, was a problem. Its present position between these two species groups is therefore considered quite acceptable (Figs. 3, 4). B. tenuispina, however, apparently has the same clasper protrusion as found in the loriae group and due to the position of that species, the most parsimonious reconstruction does not recognize that character as apomorphous for the $B$. loriae subgroup so that the species of that subgroup appear as paraphyletic in the strict consensus tree (Fig. 7). Consequently, this character must have been lost in the other subgroup of the loriae group. Several other presumed apomorphies, shared by $\boldsymbol{B}$. fortuini, $\boldsymbol{B}$. hartonoi, and $\boldsymbol{B}$. loriae, are also not recognized as such. In regard of the uncertain position of $\boldsymbol{B}$. tenuispina it is quite possible that its clasper protrusion is not homologous with that of the above-listed loriae subgroup species. Converting these species into a monophyletic group and making $\boldsymbol{B}$. hartonoi the sister species of $\boldsymbol{B}$. fortuini and $B$. loriae, as proposed here costs no less than 6 extra steps, however (Fig. 4).

The relative positions of the bloetei, exhausta, and loriae groups was considered uncertain in previous publications and a tentative cladogram has been published in which these groups form a 


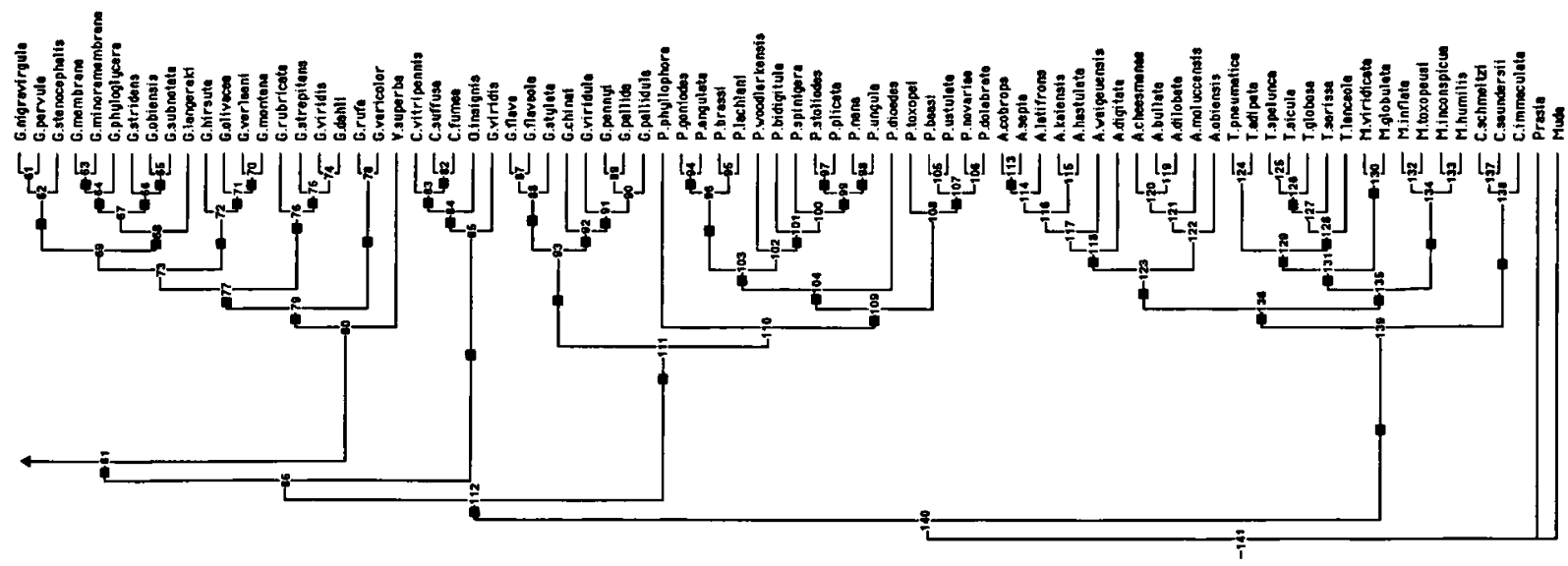

Fig. 4. (Cont.).

polytomy with the remaining part of Baeturia (De Boer, 1994 a, b, c). The here presented most parsimonious reconstruction is regarded as good as any. None of the branches responsible for this particular solution are supported by distinct and unambiguous apomorphies. The weakness of this part of the cladogram is illustrated by the fact that swapping the position of any two of the three groups would cost only 1 step. A cladogram for the species groups of Baeturia as presented in Fig. 8 seems the most realistic in view of the data available.

\section{Scottotympana}

The phylogeny and position of Scottotympana (Fig. 4) is identical to that in the strict consensus

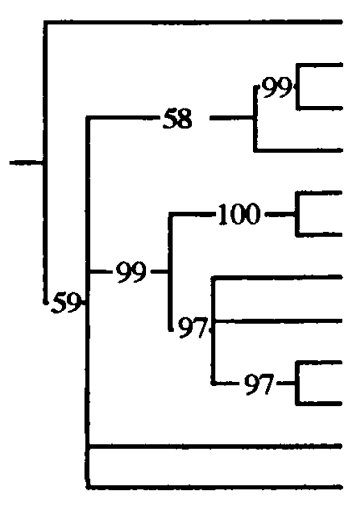
B. marmorata
B. nasuta
B. guttulipennis
B. parva
B. mamillata
B. arabuensls
B. gibberosa
B. bipunctata
B. Iaminifor
B. retracta
B. Intermedla
B. splendide

Fig. S. Section of the $50 \%$ majority rule tree dealing with the Baeturia nasuta group. Numbers refer to percentages of trees supporting the branch. tree and in accordance with earlier discussions (De Boer, 1994a, 1995a).

\section{Gymnotympana}

The phylogeny of Gymnotympana as represented in the $50 \%$ majority rule tree (Fig. 9) differs slightly from the analysis presented earlier (De Boer, 1995a), which was based on an incomplete data set. Although the earlier recognized subgroups still appear as monophyletic groups, their relative posi-

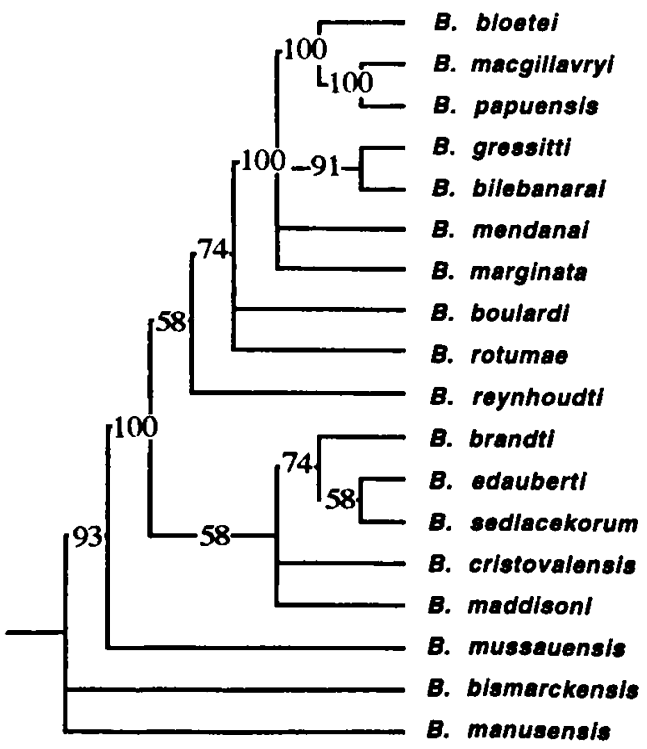

Fig. 6. Section of the $50 \%$ majority rule tree dealing with the Baeturia bloetei group. Numbers refer to percentages of trees supporting the branch. 


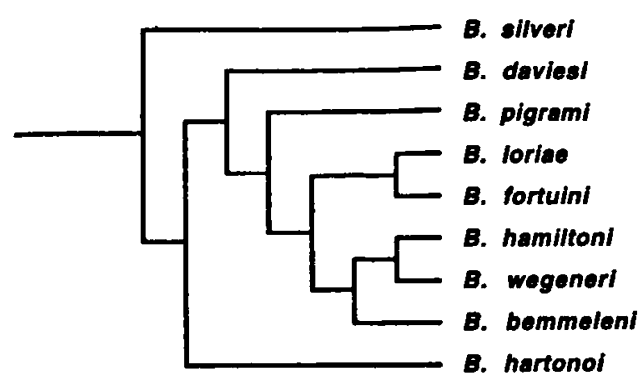

Fig. 7. Section of the strict consensus tree dealing with the Baeturia loriae group.

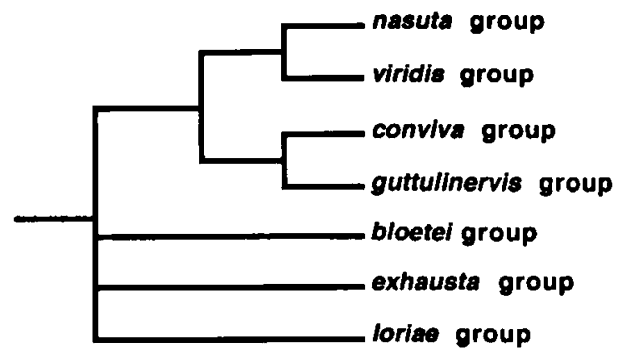

Fig. 8. Alternative cladogram for the species groups of Baeturia.

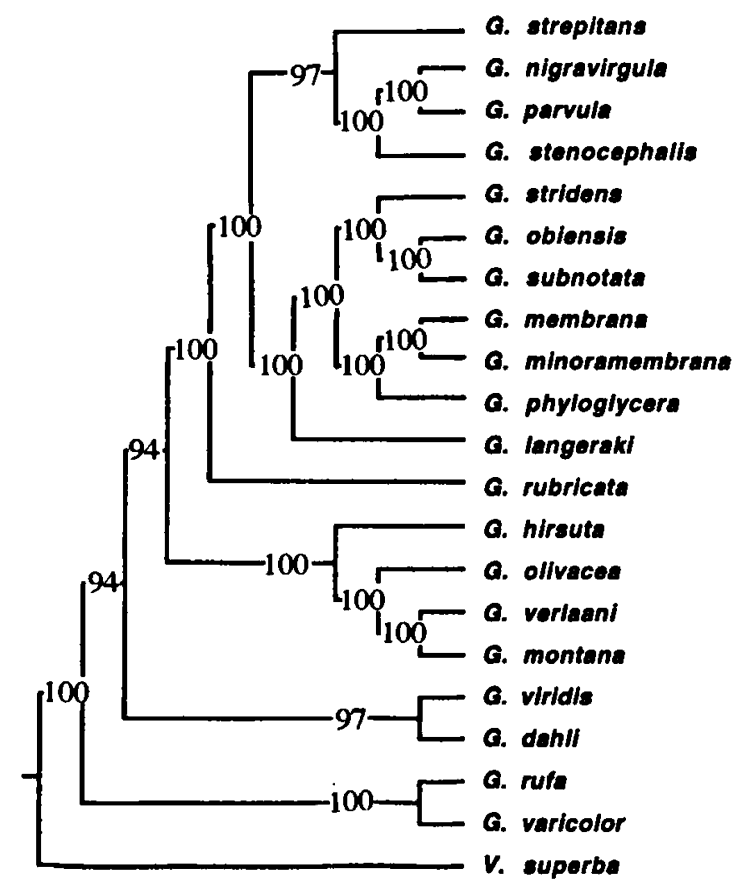

Fig. 9. Section of the $50 \%$ majority rule tree dealing with Gymnotympana. Numbers refer to percentages of trees supporting the branch. tions have slightly changed. The tree presented here is, as to these relative positions, regarded as equally acceptable as the one published before. Four species (G. dahli, G. rubricata, G. strepitans, and $G$. viridis) that are supposed to form a monophyletic group based on shared characters of the clasper, and that appeared as paraphyletic in the earlier cladogram (De Boer, 1995a) now appear as being less closely related. Converting these four species into a monophyletic group, in a then most parsimonious reconstruction of Gymnotympana as proposed here (Fig. 4) costs 4 extra steps.

\section{Venustria}

The position of the monotypic genus Venustria as sister taxon of Gymnotympana, which also appears in the strict consensus tree (Fig. 3), is in agreement with earlier proposals and here accepted as most likely. Nevertheless, two unique characters contradict this solution and suggest that Venustria should be included in Gymnotympana as in Fig. 10. $V$. superba, G. rufa, and G. varicolor share a very similar basal part of the male operculum ( 1 in Fig. 10), while $V$. superba and $G$. rufa share a distinct ventral thorn on the female genital segment ( 2 in Fig. 10) (De Boer, 1995a). The inclusion of Venustria in Gymnotympana, as is considered possible, would cost 5 extra steps.

\section{Chlorocysta, Glaucopsaltria, and Owra}

The phylogenetic reconstruction of Chlorocysta, Glaucopsaltria, and Owra, as presented in Fig. 4, is identical to that in the strict consensus tree and accepted as correct.

In an earlier discussion on the phylogeny of the Chlorocystini (De Boer, 1995a, b, c, d) the relative positions of the Australian genera complex (Chlorocysta, Glaucopsaltria, and Owra) and of the sister genera Guineapsaltria and Papuapsaltria remained uncertain; either of these groups could be the sister group of the monophyletic group containing Baeturia, Gymnotympana, Scottotympana, and Venustria. The most parsimonious solution indicates, also in the strict consensus tree, that the Australian genera form the sister group of the latter group. This solution, however, is not based on convincing synapomorphies. The weakness of this part 
of the cladogram is expressed by the fact that swapping the position of the Australian genera with that of Guineapsaltria and Papuapsaltria would make the total tree only 2 steps longer. In view of the available data, a generic cladogram with a polytomy as in Fig. 11 is a more realistic way of representing these uncertainties.

\section{Guineapsaltria}

The most parsimonious reconstruction of Guineapsaltria in the $50 \%$ majority rule tree (Fig. 12a) is largely in agreement with the earlier discussion on the phylogeny of that genus (De Boer, 1993b). The only problem forms the ambiguous position of $G$. chinai. This species shares a similar clasper with $G$. pallida, $G$. pallidula, and $G$. viridula, but a similar postclypeus with $G$. flava, G. flaveola, and $G$. stylata, and has a, presumably plesiomorphous, narrower vertex than other species of Guineapsaltria. Consequently, G. chinai is placed at the base of the cladogram of Guineapsaltria. The striking similarities in the unique clasper shape of $G$. chinai, G. pallida, G. pallidula, and G. viridula, however, are regarded as convincing evidence for the monophyly of that group, though possibly including the deviating $G$. pennyi. Changing the position of $G$. chinai to that group, as proposed here (Fig. 4), costs 2 extra steps.

\section{Papuapsaltria}

The monophyly of the genus Papuapsaltria was considered doubtful, since its presumed apomorphy, a reduced femoral spine, is not found in all species of the genus (De Boer, 1995c). Several monophyletic groups were recognized within $\mathrm{Pa}$ puapsaltria and it was stated that a subgroup with a mainly northwestern New Guinea distribution showed similarities in tegmen venation with Guineapsaltria. Two species, $P$. phyllophora and $P$. woodlarkensis, were tentatively placed at the base of the cladogram since their characters did not give a clue to a possible sister-group relationship with other species (groups) of the genus. In this light, it is remarkable that the computer analysis involving all characters comes up with two equally parsimonious solutions. In Fig. 12b, Papuapsaltria is paraphyletic, with the northwestern New Guinea species as sister group of Guineapsaltria and the re-

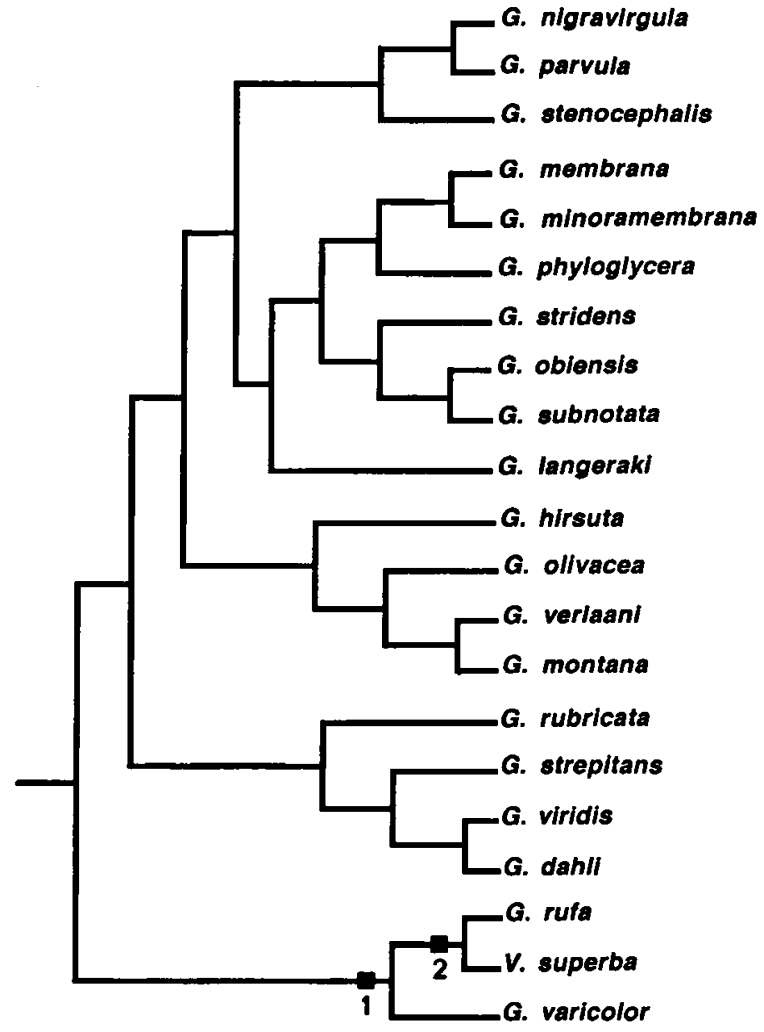

Fig. 10. Cladogram of Gymnotympana with Venustria included Numbers refer to characters discussed in the text.

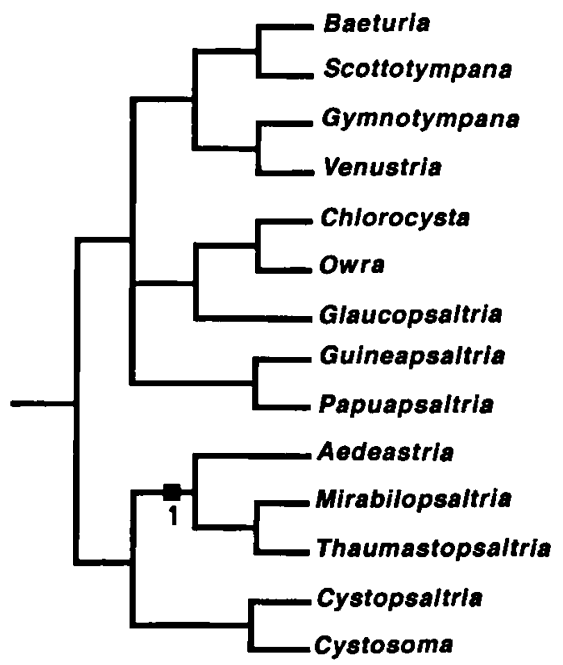

Fig. II. Generic cladogram of the Chlorocystini with a polytomy for the groups Baeturia-Venustria, Chlorocysta-Glaucopsaltria, and Guineapsaltria-Papuapsaltria. Number refers to character discussed in the text. 

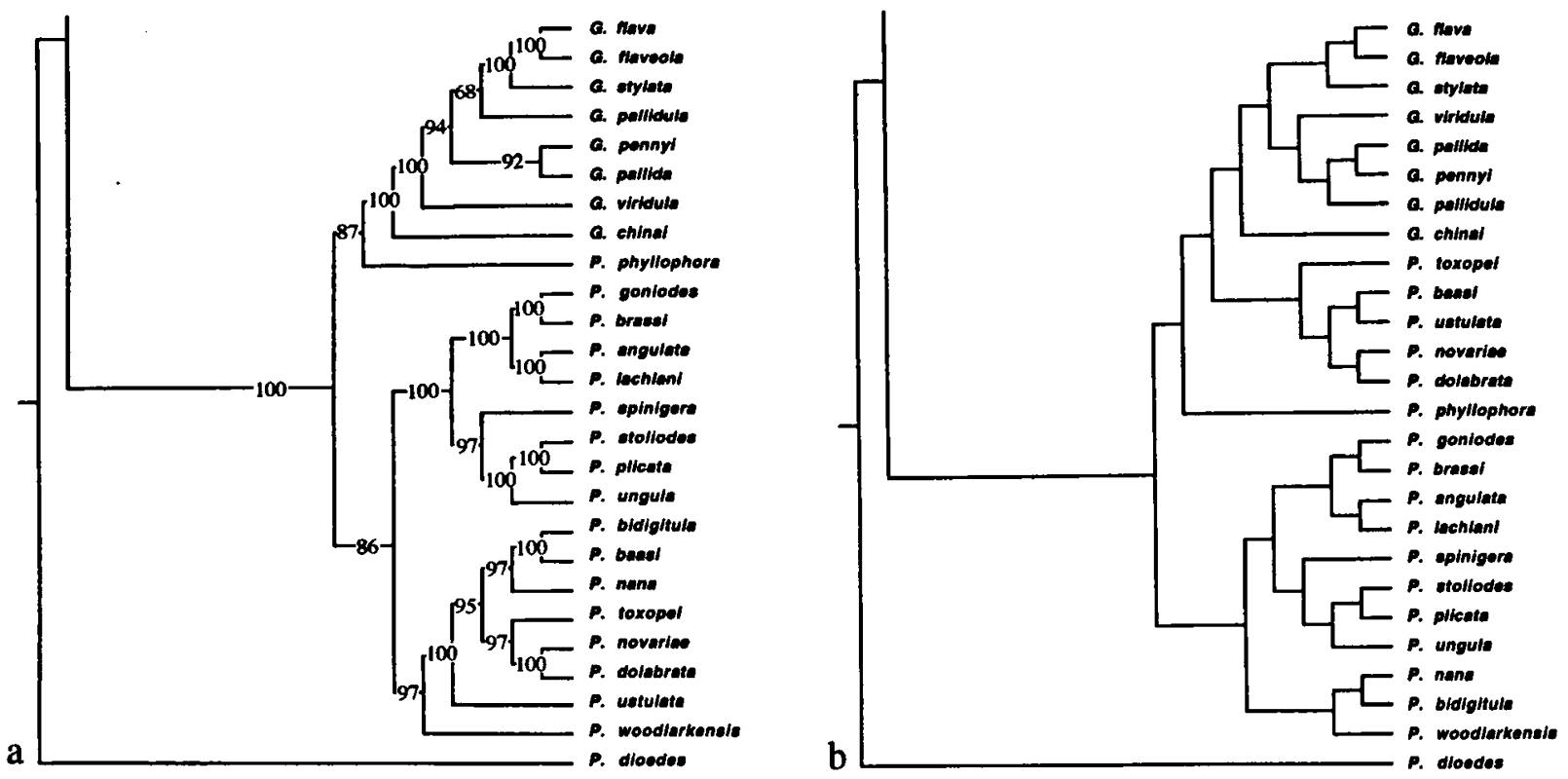

Fig. 12. (a), Section of the $50 \%$ majority rule tree dealing with Guineapsaltria and Papuapsaltria, numbers refer to percentages of trees supporting the branch; (b), alternative phylogenetic reconstruction for the genera Guineapsaltria and Papuapsaltria, with a paraphyletic genus Papuapsaltria.

maining species as sister group of these two groups combined. In Fig. 12a, Papuapsaltria is practically monophyletic.

In both these options, which are in principle regarded equally plausible, $\boldsymbol{P}$. dioedes is excluded from Papuapsaltria and figures as sister taxon to all the above-discussed genera together (cf. Fig. 3). $P$. dioedes differs strongly from other Papuapsaltria species by several presumably autapomorphous male genital characters, but the species does share the presumed apomorphous reduced femoral spine and certainly should be included somewhere within Papuapsaltria. Besides, the suggested monophyly of the group including all genera discussed above and excluding $\boldsymbol{P}$. dioedes is based on the presumed apomorphous but strongly fluctuating character of a broadly rounded pygofer opening, which certainly does not characterise that group as a whole and is considered meaningless at this level of the cladogram. Including $\boldsymbol{P}$. dioedes in Papuapsaltria in a most parsimonious position costs 3 extra steps in both the monophyletic alternative (Fig. 4) and the paraphyletic solution (Fig. 12c).

The position of $P$. dioedes is very uncertain, however. This is demonstrated by the fact that its position in the paraphyletic construction as either the sister group of Guineapsaltria, or of toxopeidolabrata, or of phylophora, or of Guineapsaltria-phyllophora, or of goniodes-ustulata, or of goniodes-woodlarkensis, is equally parsimonious. The two most parsimonious alternatives (Figs. 12a, b) show several other differences with the earlier cladogram (De Boer, 1995c). In both alternatives, and in the strict consensus tree, $\boldsymbol{P}$. goniodes and $\boldsymbol{P}$. brassi (based on five tymbal ridges and a broader vertex) and $\boldsymbol{P}$. angulata and $\boldsymbol{P}$. lachlani (based on a slender male caudodorsal beak) are sister species, while in the previous cladogram (De Boer, 1995c) $\boldsymbol{P}$. goniodes and $\boldsymbol{P}$. angulata (based on a similar male operculum) and $P$. lachlani and $P$. brassi (based on an extremely long aedeagus) are supposed to be sister species. The latter character is difficult to quantify, and was not included in the matrix. Still, this latter option is preferred here, although it is two steps longer in both alternatives (Figs. 4, 12c).

The northwestern New Guinea subgroup that was recognized before ( $P$. baasi, $P$. dolabrata, $P$. nova- 


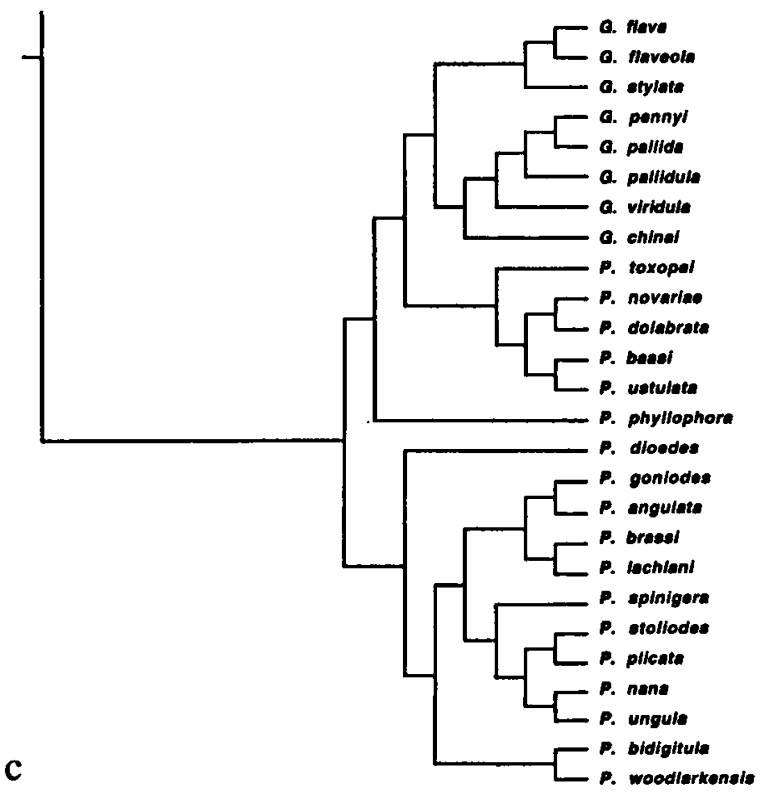

Fig. 12. (c), Most parsimonious McClade reconstruction for the genera Guineapsaltria and Papuapsaltria in the alternative version with a paraphyletic genus Papuapsaltria, and after including the modifications suggested.

riae, $P$. ustulata) is recognized in the paraphyletic option but not in the monophyletic one. In the latter option $\boldsymbol{P}$. nana and $\boldsymbol{P}$. bidigitula are included in that group, based on an in other parts of the tree strongly variable character of the postclypeus. In both these options, the likewise northwestern New Guinea species $\boldsymbol{P}$. toxopei is included in this group. In the cladogram presented earlier (De Boer, 1995c) $P$. nana and $P$. bidigitula were included in a monophyletic group with $P$. plicata, $P$. spinigera, $P$. stoliodes, and $P$. ungula, with $P$. nana as sister species of $\boldsymbol{P}$. ungula, which was based on several convincing apomorphies in the clasper. Removing these species, as proposed here, to their more credible position minimally costs 2 extra steps in both the monophyletic option (Fig. 4) and the paraphyletic one (Fig. 12c).

The phylogenetic position of $P$. woodlarkensis remains dubious; in the paraphyletic option the species is included in the Papuan group, and in the monophyletic option in the northwestern New Guinea group, but after the proposed changes its most parsimonious position is in the Papuan group in the latter option as well. Furthermore, after these changes, the most parsimonious position of $\boldsymbol{P}$. phyllophora is no longer at the base of Guineapsaltria, but at the base of Papuapsaltria.

\section{Aedeastria}

The most parsimonious reconstruction of Aedeastria in the 50\% majority rule tree (Fig. 13) is almost identical to that in the strict consensus tree, but completely differs from earlier conclusions on its phylogeny (De Boer, 1993a). The earlier proposed monophyly of a group consisting of $A$. digitata, $A$. cobrops, $A$. kaiensis, $A$. latifrons, $A$. sepia, and $A$. waigeuensis which was recognized on the basis of a unique bicuspidate clasper (De Boer, 1993a), is not recognized in the computer analysis (in that earlier phylogenetic discussion $A$. cheesmanae was abusively exchanged for $\boldsymbol{A}$. waigeuensis). Instead, the remaining species of the genus form a monophyletic group, based on a hook-shaped and apically pointed clasper, a character which frequently occurs in many other genera. Converting the abovelisted species into a monophyletic group as proposed here costs 7 extra steps in the then most parsimonious solution (Fig. 4), but only 6 extra steps in the reconstruction with a paraphyletic genus Papuapsaltria which gives a slightly different solution (Fig. 14). A. hastulata is in a most parsimonious solution part of this group in both cases.

The position of Aedeastria, either as sister group of Mirabilopsaltria and Thaumastopsaltria (based on a shared wrinkled vertex with distinct diverging fissures, 1 in Fig. 11), or as sister group of all abovediscussed genera together (based on a shared erect femoral spine, 1 in Fig. 15) was discussed in several previous publications (De Boer, 1995a, b, c, d). The most parsimonious tree unambiguously recognized Aedeastria as the sister group of Mirabilopsaltria and Thaumastopsaltria, but changing Aedeastria to a sister-group position of all above-discussed genera (see Fig. 15) will make the total tree only 1 step longer and should still be considered a possibility.

\section{Thaumastopsaltria}

The cladogram of Thaumastopsaltria in the $50 \%$ majority rule tree (Fig. 13) is fully solved and in agreement with previous discussions on the phylogeny of this genus (De Boer, 1992a). 


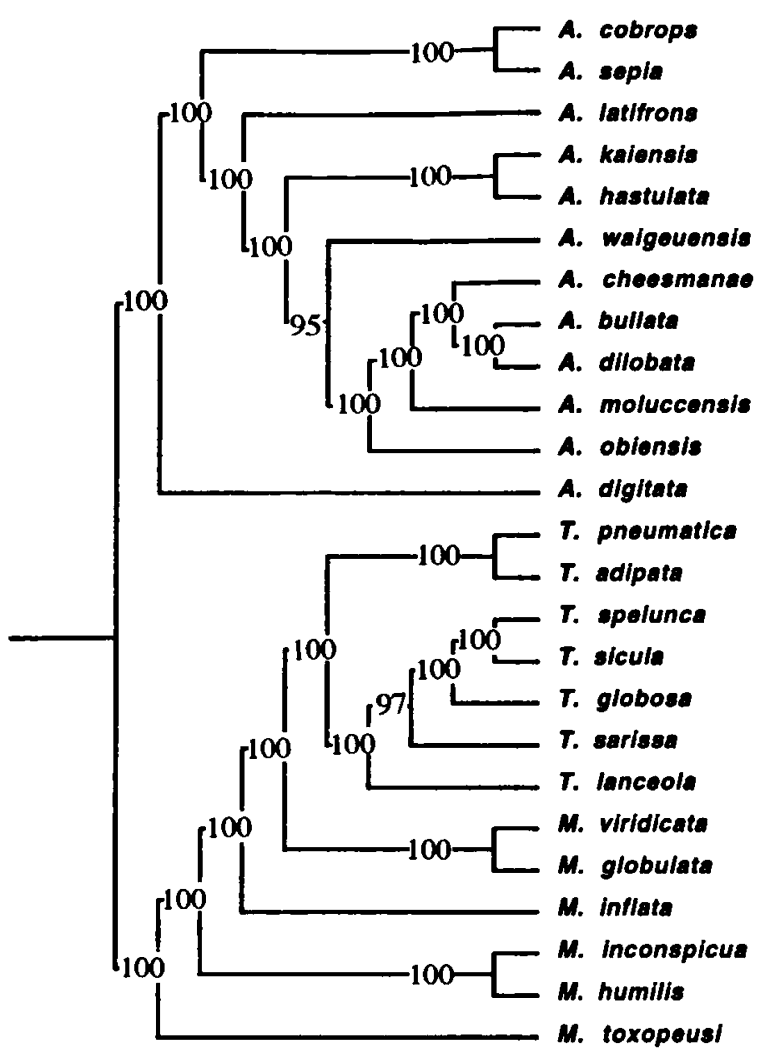

Fig. 13. Section of the $50 \%$ majority rule tree dealing with Aedeastria, Thaumastopsaltria, and Mirabilopsaltria. Numbers refer to percentages of trees supporting the branch.

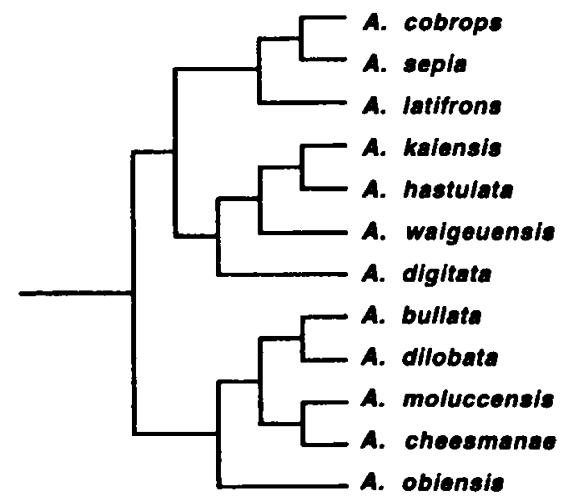

Fig. 14. Most parsimonious McClade reconstruction of Aedeastria in the alternative version with a paraphyletic genus $P a p u-$ apsaltria, and after including the modifications suggested.

\section{Mirabilopsaltria}

The monophyly of Mirabilopsaltria was considered uncertain (De Boer, 1995b). The presumed apo-

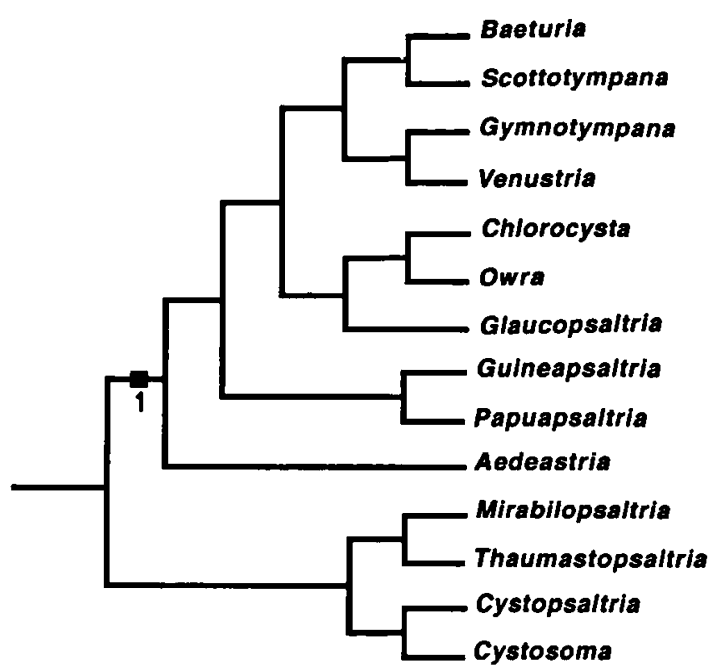

Fig. 15. Generic cladogram of the Chlorocystini with an alternative bosition for Aedeastria. Number refers to character discussed in the text.

morphy in clasper shape is not present in $M$. viridicata and, though possibly changed beyond recognition, in $M$. globulata. This presumed apomorphy is not recognized in the most parsimonious tree, not for Mirabilopsaltria as a whole and not for the species that do have that character. In the $50 \%$ majority rule tree (Fig. 13) the species of Mirabilopsaltria appear as a paraphyletic sister group of Thaumastopsaltria. The characters in support of this paraphyletic reconstruction are, with a possible exception of the one determining $M$. viridicata and $M$. globulata as the immediate sister group of Thaumastopsaltria (an extremely long 1st apical area in the tegmen), considered less convincing than the clasper character. $M$. humilis, $M$. inconspicua, $M$. inflata, and $M$. toxopeusi are still supposed to form a monophyletic group (Fig. 4). This option is proposed here and makes the tree 2 steps longer. Although the inclusion of $M$. viridicata and $M$. globulata into a monophyletic genus Mirabilopsaltria is still a possibility to be considered, depending on the possible homology of the $M$. globulata clasper with that of the other species of Mirabilopsaltria, their sister-group relationship to Thaumastopsaltria now seems more likely. Including these species in Mirabilopsaltria would cost no less than 4 extra steps. 


\section{Cystopsaltria and Cystosoma}

The basal position of Cystopsaltria and Cystosoma in the most parsimonious reconstruction (Fig. 3) is caused by the several characters these genera share with the outgroup Prasia. The there suggested monophyly of the Chlorocystini excluding Cystopsaltria and Cystosoma is based on two very unconvincing characters that cannot be regarded as representative for that group. In previous discussions on the phylogeny of the Chlorocystini (De Boer, 1995a, b, c, d) it was suggested that Cystopsaltria and Cystosoma formed the sister group of Mirabilopsaltria and Thaumastopsaltria, either or not including Aedeastria (see above) based on the narrow tymbal cavity shared by Cystosoma and most species of Mirabilopsaltria and Thaumastopsaltria; this solution is still regarded as more credible. Moving Cystopsaltria and Cystosoma to the base of Aedeastria, Mirabilopsaltria, and Thaumastopsaltria as proposed here costs only 1 step more (Fig. 4). The ingroup phylogeny of Cystopsaltria and Cystosoma given in Fig. 4 is identical to that of the strict consensus tree.

\section{Conclusions}

The final tree which contains all of the presumed synapomorphies and deals with the remaining characters in a most parsimonious way is still considered to have two equally likely solutions for the genus Papuapsaltria (Figs. 4, 12c). The option with a monophyletic solution for Papuapsaltria has a length of 906 steps, the paraphyletic option has 905 steps in its shortest acceptable solution. Apart from the Guineapsaltria-Papuapsaltria part of the cladogram these alternatives only differ slightly in a most parsimonious reconstruction of Aedeastria and the Baeturia nasuta group.

The results of this phylogenetic analysis, together with the biogeographical data discussed in previous publications (De Boer, 1982 and later works), provide the data for an area cladistic study of the New Guinea-West Pacific region. A comparison of area cladograms with data on the palaeogeology of the area in question suggests that the main speciation events that led to the present-day generic diversity in the Chlorocystini (sensu stricto) are caused by vicariance following the fragmentation of a historical volcanic island arc (De Boer, 1995d). The phylogenetic reconstruction with a paraphyletic genus Papuapsaltria (Fig. 12c) which separates the genus roughly in a western and eastern species group, appears to agree best with the historical explanations provided in that publication. Similarly, a paraphyletic option for the genus Mirabilopsaltria, which turns out to be the most parsimonious solution (Fig. 4), better fits the historical explanations. Furthermore, a position of Guineapsaltria-Papuapsaltria as sister group to the group BaeturiaVenustria, of which the possibility is discussed above (cf. Fig. 11) is in biogeographical sense slightly more parsimonious than the option given in Fig. 4 , since the latter requires the extinction of a group in a missing area (De Boer, 1995d).

\section{Acknowledgements}

I am most grateful to Dr. W.N. Ellis for running the PAUP analyses on his computer. Prof. F.R. Schram, Dr. R. Sluys, and Dr. J.P. Duffels are thanked for their critical reading and comments on the manuscript. I thank Mr. D.A. Langerak for his help in preparing the figures.

\section{References}

Boer, A.J. de, 1982. The taxonomy and biogeography of the nasuta group of the genus Baeturia Stål, 1866 (Homoptera, Tibicinidae). Beaufortia, 32(4): 57-78.

Boer, A.J. de, 1986. The taxonomy and biogeography of the conviva group of the genus Baeturia Stål, 1866 (Homoptera, Tibicinidae). Beaufortia, 36(7): 167-182.

Boer, A.J. de, 1989. The taxonomy and biogeography of the bloetei group of the genus Baeturia Stål, 1866 (Homoptera, Tibicinidae). Beaufortia, 39(1): 1-43.

Boer, A.J. de, 1990. Aedeastria, a new cicada genus from New Guinea, its phylogeny and biogeography (Homoptera, Tibicinidae), preceded by a discussion on the taxonomy of New Guinean Tibicinidae. Beaufortia, 40(3): 63-72.

Boer, A.J. de, 1991. Scottotympana, a new cicad genus from New Guinea, with the description of three new species, their taxonomy and biogeography (Homoptera, Tibicinidae). Beaufortia, 42(1): 1-11.

Boer, A.J. de, 1992a. The taxonomy and biogeography of the genus Thaumastopsaltria Kirkaldy, 1900 (Homoptera, Tibicinidae). Beaufortia, 43(3): 17-44. 
Boer, A.J. de, 1992b. The taxonomy and biogeography of the viridis group of the genus Baeturia Stål, 1866 (Homoptera, Tibicinidae). Bijdr. Dierk., 61(3): 163-183.

Boer, A.J. de, 1993a. Ten new species of the genus Aedeastria De Boer, 1990, with notes on the taxonomy and biogeography (Homoptera, Tibicinidae). Beaufortia, 43(9): 140-167.

Boer, A.J. de, 1993b. Guineapsaltria, a new genus of the Australian-New Guinean region, with notes on its taxonomy and biogeography (Homoptera, Tibicinidae). Bijdr. Dierk., 63(1): 15-41.

Boer, A.J. de, 1994a. The taxonomy and biogeography of the exhausta group of the genus Baeturia Stål, 1866 (Homoptera, Tibicinidae). Beaufortia, 44(5): 127-158.

Boer, A.J. de, 1994b. The taxonomy and biogeography of the guttulinervis group of the genus Baeturia Stål, 1866 (Homoptera, Tibicinidae). Bijdr. Dierk., 64(2): 87-100.

Boer, A.J. de, 1994c. The taxonomy and biogeography of the loriae group of the genus Baeturia Stål, 1866 (Homoptera, Tibicinidae). Tijdschr. Ent., 137: 1-26.

Boer, A.J. de, 1994d. Four species added to the Baeturia nasuta group, with notes on taxonomy and biogeography (Homoptera, Tibicinidae). Tijdschr. Ent., 137: 161-172.

Boer, A.J. de, 1995a. The taxonomy, phylogeny and biogeography of the cicada genus Gymnotympana Stall, 1861 (Homoptera: Tibicinidae). Invert. Taxon., 9(1): 1-81.

Boer, A.J. de, 1995b. Mirabilopsaltria, a new cicad genus from New Guinea, its taxonomy and biogeography (Homoptera, Tibicinidae). Trop. Zool. (in press).

Boer, A.J. de, 1995c. The taxonomy and biogeography of the genus Papuapsaltria n. gen. (Homoptera, Tibicinidae). Tijdschr. Ent., 138: 1-44.

Boer, A.J. de, 1995d. Islands and cicadas adrift in the westPacific; biogeographic patterns related to plate tectonics. Tijdschr. Ent., 138: 169-244.

Boulard, M., 1975a. Les Cigales des savanes centrafricaines. Systématique, notes biologiques et biogéographiques. Bull. Mus. natn. Hist. nat., (3) 315: 869-928.

Boulard, M., 1975b. Données nouvelles sur les Cigales angolaises. Instituto de investigaçao agronómica de Angola, Sér. cientifica, 40: 1-22.

Boulard, M., 1976. Sur une deuxième Cigale africaine dépourvue d'appareil sonore (Homoptera). Bull. Inst. fond. Afr. noire, 37 (Sér. a): 629-636.

Boulard, M., 1979. Révision de la faune cicadéenne des Iles Maurice et Rodriguez. Bull. Soc. ent. Fr., 84: 27-47.

Boulard, M., 1981a. Sur trois Toxopeusella nouvelles des collections du British Museum (Hom. Cicadoidea). Entomologist's mon. Mag., 117: 129-138.

Boulard, M., 1981b. Recherches zoologiques en Ethiopie: Homoptera Cicadoidea. Quad. Accad. naz. Lincei, Roma, 252: $57-60$.

Boulard, M., 1990. Contributions à l'entomologie générale et appliquée, 2. Cicadaires (Homoptères Auchenorhynques) Première partie: Cicadoidea. EPHE, Trav. Lab. Biol. Evol. Insectes, 3: 55-245.

Dlabola, J., 1958. First contribution to the knowledge of the Cicadidae from the Belgian Congo (Homoptera, Auche- norrhyncha). Acta ent. Mus. natn. Pragae, 32: 317-352.

Dlabola, J., 1960. Cicadidae (Hemiptera, Homoptera, Auchenorrhyncha). Explor. Parc natn. Upemba, Miss. G.F. de Witte, 59(2): 9-37.

Duffels, J.P., 1993. The systematic position of Moana expansa (Homoptera, Cicadidae), with reference to sound organs and the higher classification of the superfamily Cicadoidea. $\mathbf{J}$. nat. Hist., 27: 1223-1237.

Duffels, J.P. \& A.J. de Boer, 1990. Areas of endemism and composite areas in East Malesia. In: P. Baas, C. Kalkman \& R. Geesink (eds.), The plant diversity of East Malesia; Proceedings of the Flora Malesiana symposium commemorating Professor Dr. C.G.G.J. van Steenis, Leiden, August 1989: 249-272 (Kluwer Academic Publishers, Dordrecht).

Duffels, J.P. \& P.A. van der Laan, 1985. Catalogue of the Cicadoidea (Homoptera, Auchenorhyncha) 1956-1980. Series Entomologica, 33: i-xvi, 1-414.

Farris, J.S., 1969. A successive approximations approach to character weighting. Syst. Zool., 18: 374-385.

Hennig, W., 1950. Grundzüge einer Theorie der phylogenetischen Systematik: 1-370 (Deutscher Zentralverlag, Berlin).

Hennig, W., 1966. Phylogenetic systematics: 1-263 (University of Illinois Press, Urbana).

Jong, M.R. de, 1982. The Australian species of the genus Lembeja Distant 1892 (Homoptera, Tibicinidae). Bijdr. Dierk., 52(2): 175-185.

Jong, M.R. de, 1985. Taxonomy and biogeography of Oriental Prasiini 1: The genus Prasia Stål, 1863 (Homoptera, Tibicinidae). Tijdschr. Ent., 128: 165-191.

Jong, M.R. de, 1986. Taxonomy and biogeography of Oriental Prasiini 2: The foliata group of the genus Lembeja Distant, 1892 (Homoptera, Tibicinidae). Tijdschr. Ent., 129: 141180.

Jong, M.R. de, 1987. Taxonomy and biogeography of Oriental Prasiini 3: The fatiloqua and parvula groups of the genus Lembeja Distant, 1892 (Homoptera, Tibicinidae). Tijdschr. Ent., 130: 177-209.

Jong, M.R. de \& J.P. Duffels, 1981. The identity, distribution and synonymy of Lembeja papuensis Distant, 1897 (Homoptera, Tibicinidae). Bull. zoöl. Mus. Univ. Amsterdam, 8(7): 53-62.

Maddison, W.P. \& W.R. Maddison, 1992. MacClade: Analysis of phylogeny and character evolution, version 3 (Sinauer Associates, Sunderland, Massachusetts).

Metcalf, Z.P., 1963a. General catalogue of the Homoptera VIII. Part 1 Cicadidae, sect. I Tibiceninae: i-vii, 1-585, sect. Il Gaeaninae and Cicadinae: 587-919 (North Carolina State College, Raleigh, N.C.).

Metcalf, Z.P., 1963b. General catalogue of the Homoptera, VIII. Part 2. Tibicinidae: i-iv, 1-492 (North Carolina State College, Raleigh, N.C.).

Moulds, M.S., 1990. Australian cicadas: 1-217 (New South Wales University Press, Kensington).

Orian, A.J.E., 1954. A synopsis of the Cicadidae of Mauritius, with a description of Mauricia claudeae, gen. et sp. n. Ann. Mag. nat. Hist., (12) 7: 233-237, pl. V. 
Orian, A.J.E., 1964. The morphology of the male genitalia of Abricta ferruginosa (Stál) (Homoptera, Cicadidae). Proc. R. ent. Soc. London, (A) 39(1-3): 1-4.

Swofford, D.L., 1993. PAUP: Phylogenetic Analysis Using Parsimony, version 3.1.1 (computer program distributed by the Illinois Natural History Survey, Champaign, Illinois).

Villet, M.H., 1993. The cicada genus Bavea Distant, 1905 (Homoptera, Tibicinidae): redescription, distribution and phylogenetic affinities. Trop. Zool., 6(2): 435-440.

Received: 24 July 1995

Revised: 12 October 1995

\section{Appendix 1. List of characters}

\section{Colour}

1 Body colour: (1) unspeckled, (2) speckled with brown

2 Colour of female: (1) uniformly coloured, (2) bicoloured: head and thorax green, abdomen ochraceous

Head

3 Postclypeus: (1) anteriorly rounded, (2) with sharp anterior edge

4 Anterior margin of postclypeus in dorsal view: (1) continuous with anterior margins of vertex lobes, (2) convexly protruding beyond vertex lobes, (3) strongly curving back laterally and making almost right angle with vertex lobes

5 Postclypeus in lateral view: (1) not swollen, (2) angularly swollen, (3) globularly swollen, (4) protruding in obtuse angle, (5) with convex anterior margin

6 Lateral sides of postclypeus: (1) without posterior ridge along lorum, (2) with swollen posterior ridge along lorum

7 Lateral sides of postclypeus: (1) with distinct rasps of rows of short parallel ridges, (2) with very short and indistinct rows of parallel ridges, (3) without rows of parallel ridges

8 Vertex: (1) without dark spots, (2) with dark spots between eyes and lateral ocelli

9 Medial part of vertex: (1) distinctly rising from postclypeus, (2) very flat, (3) slightly indented

10 Surface of vertex: (1) smooth, (2) with distinct fissures diverging from centre of head to corners of postclypeus

11 Distance between lateral ocelli: (1) hardly exceeding width of frontal ocellus, (2) distinctly larger than width of frontal ocellus

12 Distance between lateral ocelli: (1) about equalling distance between lateral ocellus and eye, (2) generally slightly larger than distance between lateral ocellus and eye, (3) generally distinctly larger than distance between lateral ocellus and eye

\section{Pronotum}

13 Pronotal surface: (1) smooth, (2) mottled

14 Pronotum: (1) without dark medial spot, (2) with dark medial spot at pronotal collar
15 Pronotum: (1) without coloured medial band, (2) with dark streaks along light medial band, (3) with darkened medial band

16 Pronotum: (1) without distinct medial furrow, (2) with distinct medial furrow

17 Anterolateral side of pronotal collar: (1) rounded, (2) swollen, (3) angularly bent, (4) forming continuous ridge

Mesonotum

18 Mesonotal colouring: (1) without spots in front of cruciform elevation, (2) two black spots in front of cruciform elevation

19 Cruciform elevation: (1) wider than long, (2) narrower than long

Legs

20 Proximal spine of fore femur: (1) erect, (2) bent adjacent to femur

21 Proximal spine of fore femur: (1) of normal length, (2) extremely long, (3) reduced

22 Proximal spine of fore femur: (1) not shorter than distance to middle spine, (2) distinctly shorter than distance to middle spine, (3) slightly shorter than distance to middle spine

23 Middle spine of fore femur: (1) narrow spiny, (2) broad triangular

Tegmina and wings

24 Colour of tegmen: (1) hyaline, (2) opaque greenish or reddish, (3) slightly reddish but still hyaline, (4) bronzed

25 Colour markings on tegmen: (1) immaculate, (2) brown spots along veins, (3) triangular brown spots at ends of apical areas

26 Shape of tegmen: (1) rounded at apex, (2) pointed at apex

27 Tegmen venation: (1) not reticulate, (2) reticulate

28 Hyaline hind margin of tegmen: (1) very narrow, (2) narrow but distinct, (3) broad

29 Costal area of tegmen: (1) narrow to apex, (2) widening to apex

30 Number of apical areas in tegmen: (1) eight, (2) eight or nine, (3) nine, (4) nine or ten, (5) variable between nine and fifteen, (6) more than twenty

31 Ultimate apical area of tegmen: (1) quadrangular, (2) triangular

32 Subapical areas of tegmen: (1) absent, (2) present but not forming a continuous band, (3) forming a continuous band, (?) not clear due to reticulate venation

33 Base of first apical area of tegmen: (1) distally of base of third apical area, (2) slightly proximally of base of third apical area, (3) distinctly proximally of base of third apical area

34 Veins of tegmen: (1) without or practically without setae, (2) densely set with setae

35 Number of apical areas in wing: (1) six, (2) five, (3) six or seven, (4) seven or more

36 Sexual dimorphism in anal fields of wing: (1) absent, (2) present 
Tymbal organ

37 Tymbal: (1) parallel to lateral side of abdomen, (2) strongly curved inwards towards its ventral corner

38 Number of tymbal ridges: (1) four ridges or less, (2) five ridges, (3) six ridges, (4) seven ridges, (5) eight ridges, (6) ten ridges, (7) eleven ridges or more

39 Tymbal ridges: (1) parallel, (2) aberrant

40 Tymbal ridges: (1) not curved around intercalary ridges, (2) curved around intercalary ridges

41 Tymbal cavity: (1) broad, (2) narrow

\section{Opercula}

42 Male opercula: (1) widely separated, (2) juxtaposed medially

43 Male operculum: (1) longer than meracanthus, (2) shorter than meracanthus

44 Male operculum: (1) not completely covering tymbal cavity, (2) completely covering tymbal cavity

45 Male operculum: (1) not elongate at medial margin, (2) elongate at medial margin

46 Basal part of male operculum: (1) distinctly vaulted, (2) strongly curved down medially, (3) hardly vaulted

47 Basal part of male operculum: (1) almost oblong, (2) laterally longer than medially, (3) laterally shorter than medially and abruptly lengthening, (4) laterally shorter than medially and gradually lengthening

48 Lateral crest of operculum base: (1) normally developed, (2) very long and slender

49 Shape of distal part of male operculum: (1) angularly oval, (2) squarely rounded, (3) blunt triangular and flat, (4) blunt triangular with straight lateral margin, (5) triangular and domed, (6) small and rounded, (7) small and angular

50 Lateral margin of male operculum: (1) not continuous to distolateral corner of operculum base, (2) continuous to distolateral corner of operculum base

51 Distomedial margin of male operculum: (1) without recurving rim, (2) with recurving rim

52 Medial margin of male operculum: (1) medially of meracanthus, (2) laterally of meracanthus

53 Meracanthus in male: (1) normally developed, (2) strongly reduced

54 Distal part of female operculum: (1) rectangular oblong, (2) trapezoid, (3) narrow sickle-shaped, (4) broad sickleshaped, (5) continuous to distolateral corner of basal part, (6) triangular

\section{Abdomen}

S5 Male abdomen: (1) not transparent, (2) transparent

56 Male abdomen: (1) rounded lateroventrally, (2) tergites sharply folded lateroventrally

57 Abdominal sternites: (1) without medial band, (2) with red medial band

58 First sternite of male: (1) short; broader than long, (2) long; longer than broad

59 Eighth sternite of male: (1) not sharply incised, (2) sharply incised at distal margin

60 Second tergite of male: (1) swollen along tymbal, (2) not swollen but folded inwards along tymbal, (3) forming a distinct ridge along tymbal

61 Second tergite of male: (1) forming a distinct ridge along tymbal cavity, (2) not forming a distinct ridge along tymbal cavity

62 Second tergite of male: (1) not membranous, (2) membranous opposite tymbal

63 Second tergite of male: (1) not swollen, (2) swollen along tymbal cavity

64 Eighth tergite of male: (1) not forming ventral lobe, (2) forming small posteriorly projecting ventral lobe

65 Male auditory capsule: (1) swollen and protruding, (2) not swollen and not protruding

66 Pygofer and 9th sternite: (1) resting on 8th sternite, (2) elevated respective to 8 th sternite

67 Connecting bar between tymbal and abdomen: (1) not elongate, (2) strongly elongate

68 Connecting bar between tymbal and abdomen: (1) parallel to body axis, (2) directed mesiad

Male pygofer

69 Pygofer: (1) not curved to ventral position, (2) curved to ventral position on abdomen

70 Pygofer: (1) without lateral fold, (2) with distinct fold at base of caudodorsal beak

71 Male caudodorsal beak: (1) erect and not reaching over anal valves, (2) curved and extending over anal valves, (3) absent

72 Male caudodorsal beak: (1) not covering anal valves, (2) very strongly curved and covering anal valves

73 Male caudodorsal beak: (1) erect, (2) angularly bent and dorsally flattened, (3) bent down towards apices of lateral lobes, (4) strongly rounded; continuously rounded with dorsal margin of pygofer, (5) strongly rounded but not continuous with dorsal margin of pygofer, (6) weakly curved

74 Male caudodorsal beak: (1) straight to apex, (2) concave to apex

75 Apex of male caudodorsal beak: (1) sharply pointed, (2) rounded, (3) truncate or weakly concave, (4) bicuspidate, (5) broadly rounded, (6) beak missing

76 Male caudodorsal beak in lateral view: (1) stout, (2) slender

77 Male caudodorsal beak: (1) broad at base, (2) narrow oblong, (3) spine-shaped

78 Male caudodorsal beak: (1) hollow, reversed gutter-shaped, (2) massive

79 Male caudodorsal beak in dorsal view: (1) oblong with almost parallel lateral margins, (2) triangular with converging margins

80 Protuberance on lateral lobe of pygofer: (1) narrow lobate or laminiform, (2) extremely broad and lobate

81 Protuberance on lateral lobe of pygofer: (1) not conically elongate beyond pygofer margin, (2) conically elongate beyond pygofer margin

82 Protuberance on lateral lobe of pygofer: (1) not triangularly swollen, (2) triangularly swollen iw jor,

83 Protuberance on lateral lobe of pygofer: (1) roundet, (2) with sharp lateral edge or9

84 Protuberance on lateral lobe of pygofer: (1) straightly directed posteriad, (2) upcurving towards apex 
85 Distal margin of pygofer: (1) curving to base of lateral protuberance, (2) curving to apex of lateral protuberance

86 Pygofer: (1) not broadening between lateral protuberances, (2) broadening between lateral protuberances

87 Pygofer: (1) not narrowing between lateral protuberances, (2) narrowing between lateral protuberances

88 Distal margin of pygofer: (1) weakly convex, (2) strongly convex into a distinct posterior lobe, (3) weakly concave, (4) strongly concave

89 Ventral part of pygofer: (1) not or hardly protruding, (2) forming a rectangular corner under lateral protuberance, (3) forming a thorn-shaped protuberance under lateral protuberance

90 Pygofer: (1) not swollen at ventral margin, (2) swollen at ventral margin

91 Ventral margin of pygofer: (1) straight to base, (2) strongly concave to base

92 Pygofer opening: (1) without straight basal margin, (2) with straight basal margin

93 Ventral half of pygofer opening: (1) not bordered by a continuous sharp edge, (2) bordered by a continuous sharp edge

94 Ventral half of pygofer opening: (1) not horseshoe-shaped, (2) horseshoe-shaped with incurving lateral corners

95 Ventral half of pygofer opening: (1) triangular and pointed, (2) broad and rounded, (3) with concave margins and pointed, (4) very long and slender

96 Basal margin of pygofer opening: (1) not lowered, (2) lowered

97 Anal valves: (1) not swollen, (2) swollen

Clasper

98 Claspers: (1) fused or practically fused to a more or less continuous ring around base of anal valves, (2) distinctly separated at base

99 Clasper: (1) without lateral plate, (2) with lateral plate

100 Clasper: (1) strongly bent and hook-shaped, (2) nearly straight and posteriorly directed

101 Clasper: (1) not triangular, (2) triangle-shaped in lateral view

102 Clasper: (1) not forming a shaft around aedeagus, (2) forming a shaft around aedeagus

103 Claspers: (1) parallel, (2) diverging towards apices

104 Clasper: (1) not rectangular laminiform, (2) rectangular laminiform

105 Clasper: (1) not transparent ventromedially, (2) ventromedially transparent

106 Clasper: (1) without distinct cross fold, (2) with distinct cross fold between basal part and apical part

107 Clasper base: (1) without crest protruding beyond pygofer margin, (2) with distinct lateral crest protruding beyond pygofer margin

108 Clasper base: (1) not forming clasper heel, (2) forming distinct angular dorsal corner or clasper heel

109 Clasper: (1) without dorsally protruding clasper heel, (2) with dorsally protruding clasper heel
110 Proximal parts of claspers: (1) not merged between aedeagus and anal valves, (2) merged between aedeagus and anal valves

11 Dorsal part of clasper: (1) not forming a shaft around aedeagus, (2) forming a short shaft around aedeagus

112 Claspers: (1) without sharp and converging dorsal edges, (2) with sharp and converging dorsal edges

113 Dorsal crest of clasper: (1) not angularly protruding, (2) angularly protruding at distal corner

114 Dorsal margin of clasper: (1) not rectangularly bent, (2) rectangularly bent at half-length

115 Clasper: (1) without dorsal crest, (2) with short dorsal crest on proximal half only, (3) with dorsal crest over almost whole length

116 Clasper: (1) with no or straight dorsal crest, (2) with convex dorsal crest

117 Dorsal crest of clasper: (1) erect or absent, (2) curving laterad

118 Dorsal crest of clasper: (1) absent or not forming dorsal protrusion, (2) forming dorsal protrusion

119 Dorsal protrusion of clasper: (1) absent, (2) broad laminiform, (3) narrow finger-shaped, (4) humped

120 Dorsal edge of clasper: (1) not curved around aedeagus, (2) forming a rectangular corner around aedeagus, (3) forming a rectangular crest around aedeagus, (4) forming a distinctly swollen protuberance around aedeagus, (5) globularly rounded

121 Apical part of clasper: (1) without proximal protrusion, with proximal protrusion

122 Clasper apex: (1) not swollen, (2) swollen

123 Clasper apex: (1) not globularly swollen, (2) globularly swollen

124 Clasper apex: (1) broad in dorsal view, (2) abruptly narrowing in dorsal view

125 Clasper apex: (1) pointed or rounded, (2) bicuspidate or dentate

126 Apical part of clasper in lateral view: (1) not broader than basal part, (2) broader than basal part

127 Clasper: (1) without small triangle-shaped apical part, (2) with very small triangle-shaped apical part

128 Clasper hollow: (1) long and strongly bent, (2) long and straight, (3) short and straight, (4) short and strongly bent, (5) short and downcurved, (6) different

129 Clasper: (1) without ventromedial protuberance, (2) with broad and laminiform ventromedial protuberance, (3) with narrow and spiny ventromedial protuberance

130 Clasper: (1) without distinct rim around ventral hollow, (2) with distinct rim around ventral hollow

131 Clasper: (1) without lateral process, (2) with lobate lateral process, (3) with lateral thorn, (4) with lateral crest ending in small thorn

Aedeagus

132 Aedeagus: (1) S-curved, (2) C-curved

133 Aedeagus: (1) not Z-curved in apical part, (2) Z-curved in apical part 
134 Surface of aedeagus: (1) smooth, (2) with pattern of concentric ridges

135 Orientation of aedeagus: (1) more or less erect between claspers, (2) directed posteriad parallel to and between claspers

136 Aedeagus: (1) with lateral crests, (2) with lateral lobes, (3) with elongate lateral lobes

137 Lateral lobes of aedeagus: (1) straight or absent, (2) strongly curving laterad

138 Lateral crest of aedeagus: (1) gradually tapering towards aedeagal apex, (2) ending in rectangular corner

139 Aedeagus: (1) without crest between lateral lobes, (2) with crest between lateral lobes

140 Aedeagus: (1) not swollen between lobes, (2) swollen between lobes

141 Aedeagus part distally of basal curve: (1) not long and slender, (2) extremely long and slender

142 Apical part of aedeagus: (1) not abruptly narrowing, (2) abruptly narrowing and upcurving, (3) abruptly narrowing and downcurving

143 Aedeagal apex: (1) not elongated dorsally, (2) distinctly elongated dorsally, (3) slightly elongated dorsally

144 Aedeagus: (1) without distinct subapical lobe, (2) with distinct subapical lobe

145 Aedeagus: (1) without dorsal crests, (2) with single dorsal crest, (3) with paired dorsal crests, (4) with pair of dorsolateral protuberances

146 Aedeagus: (1) without ventral crest, (2) with ventral crest or keel

147 Aedeagus from behind: (1) not bottle-shaped, (2) bottleshaped; abruptly narrowing towards apex

148 Aedeagus: (1) strongly curved and tapering to apex, (2) strongly curved and not tapering to apex, (3) weakly curved

149 Aedeagus: (1) not strongly swollen proximally, (2) strongly swollen proximally

150 Aedeagal pore: (1) narrow oval, (2) triangular and widening to broadly rounded proximally, (3) apically pointed but not widening proximally, (4) broad oval, (5) round

151 Margin of aedeagal pore in lateral view: (1) weakly concave, continuous with curve of aedeagus, (2) strongly concave, not continuous with curve of aedeagus, (3) convex, due to dorsoventral incision, (4) straight

Female genitalia

152 Ovipositor sheaths: (1) reaching to apex of caudodorsal beak, (2) reaching just beyond apex of caudodorsal beak, (3) reaching far beyond apex of caudodorsal beak

153 Apex of female caudodorsal beak: (1) sharply pointed, (2) broadly rounded, (3) narrowly rounded, (4) truncate, (5) bicuspidate

154 Female pygofer: (1) without ventral thorn, (2) with ventral thorn
Appendix 2. List of presumed apomorphies, the black squares in Fig. 4.

\begin{tabular}{ll} 
Internode & $\begin{array}{l}\text { Character } \\
\text { and state }\end{array}$ \\
\hline $4-3$ & $119-2$ \\
$5-4$ & $119-(2+3+4)$ \\
& $153-4$ \\
$7-5$ & $118-2$ \\
$9-8$ & $5-2$
\end{tabular}

Homoplasies $(\mathrm{H})$ and reversals (R)

$H$ in $B$. edauberti, O. insignis

$\mathrm{H}$ in $\boldsymbol{B}$. bemmeleni, B. daviesi, B. guttulinervis, $B$. hamiltoni,

$B$. pigrami, $B$. wauensis

$H$ in internode $66-65$

16-9 55-2

73-2

141-2

15-11 116-2

13-12 75-4

14-13 140-2

15-14 73-3

16-15 83-2

107-2

25-16 79-1

20-19 137-2

24-20 38-3

23-22 130-2

24-23 123-2

25-24 73-4

122-2

153-3

40-25 81-2

35-34 73-4

36-35 124-2

39-38 150-1

40-39 49-2

44-43 113-2

30-4

46-45 22-3

47-46 $\quad 87-2$

117-2

53-50 116-2

52-51 25-3

144-2

53-52 126-2

136-3

56-53 109-2

56-55 49-3

57-56 36-2
$\boldsymbol{R}$ in $\boldsymbol{B}$. marmorata

$H$ in internode $67-66$

$\mathrm{H}$ in internode $52-51$

$\mathbf{H}$ in internode 53-50

$\mathbf{H}$ in internode 99-97

$\mathbf{H}$ in $B$. furcillata

$\mathbf{H}$ in $\boldsymbol{B}$. inconstans

$\mathbf{H}$ in $\boldsymbol{B}$. inconstans

$\mathbf{H}$ in $B$. guttulipennis

$\mathbf{H}$ in many groups

$\mathbf{H}$ in $\boldsymbol{A}$. digitata, B. furcillata, $B$. gressitti \& internode 35-34

$\mathrm{H}$ in $\boldsymbol{B}$. gibberosa

$R$ in node $18-17$

$\mathbf{H}$ in $\boldsymbol{A}$. digitata, $\boldsymbol{B}$. furcillata,

B. gressitti \& internode 25-24

$H$ in $B$. papuensis and many groups of Baeturia

$\mathbf{H}$ in $\mathbf{B}$. rossi

$\mathrm{H}$ in B. karkarensis, B. rufa, B. turgida

$H$ in internode $15-11$

$H$ in internode $16-9$

$H$ in $B$. tenuispina

$\mathbf{H}$ in $G$. hirsuta, $G$. olivacea

$\mathbf{H}$ in internode 80-79 \& Prasia 
Appendix 2. Continued.

\begin{tabular}{lll}
\hline Internode & $\begin{array}{l}\text { Character nr. } \\
\text { and state }\end{array}$ & $\begin{array}{l}\text { Homoplasies }(\mathrm{H}) \text { and reversals } \\
\text { (R) }\end{array}$
\end{tabular}

\begin{tabular}{|c|c|c|}
\hline & $91-2$ & $\begin{array}{l}\mathrm{H} \text { in } G . \text { obiensis, } G . \text { olivacea, } \\
S . \text { huibregtsae, } V . \text { superba }\end{array}$ \\
\hline \multirow[t]{5}{*}{$60-57$} & $23-2$ & $\mathrm{H}$ in $G$. rubricata \\
\hline & $136-(2+3)$ & \\
\hline & $148-1$ & \\
\hline & $150-(1-4)$ & $\begin{array}{l}\mathrm{H} \text { in } A . \text { waigeuensis, } A . \\
\text { obiensis, internodes } 73-72 \text { \& } \\
127-126\end{array}$ \\
\hline & $151-(1+2)$ & \\
\hline \multirow[t]{2}{*}{$59-58$} & $88-2$ & $\mathrm{H}$ in internode $110-109$ \\
\hline & $99-2$ & \\
\hline \multirow[t]{4}{*}{$60-59$} & 46-2 & \\
\hline & $64-2$ & \\
\hline & $121-2$ & \\
\hline & $138-2$ & \\
\hline $81-60$ & $98-1$ & $\mathbf{H}$ in $A$. dilobata \\
\hline $69-62$ & $120-4$ & $\begin{array}{l}\text { H in G. varicolor, A. hastula } \\
\text { ta \& internode } 99-98\end{array}$ \\
\hline \multirow[t]{2}{*}{$64-63$} & $60-3$ & \\
\hline & $62-2$ & \\
\hline $67-64$ & $89-3$ & $\mathrm{H}$ in $\boldsymbol{P}$. woodlarkensis \\
\hline \multirow[t]{2}{*}{$66-65$} & $38-1$ & $\mathrm{H}$ in internode $8-9$ \\
\hline & $40-2$ & \\
\hline \multirow[t]{3}{*}{$67-66$} & $48-2$ & \\
\hline & $55-2$ & $\mathrm{H}$ in internode $16-9$ \\
\hline & $106-2$ & \\
\hline $69-68$ & $142-3$ & \\
\hline $71-70$ & $49-4$ & \\
\hline
\end{tabular}

H in M. humilis, Prasia \& internodes 131-130 \& 139-138 $H$ in $B$. inconstans, $M$. inflata, $P$. goniodes \& internodes 86-85 \& 131-129

31-2

$\mathbf{R}$ in $\mathbf{G}$. olivacea

32-2 $\mathrm{H}$ in $M$. inflata, $M$. globulata \& internode $129-128$

150-4 $\quad H$ in $A$. obiensis, $A$. waigeuensis, $G$. varicolor

76-75 127-2

77-76 148-2

79-77 37-2

79-78 47-3

57-2

80-79 36-2

86-81 52-1

83-82 38-7

84-83 133-2

85-84 35-2

86-85 30-5
$\mathrm{H}$ in $\boldsymbol{P}$. dolabrata

$H$ in $B$. inconstans, $M$. infla-
$\mathbf{R}$ in G. dahli, G. olivacea

$H$ in $V$. superba

$\mathrm{H}$ in Prasia \& internode

57-56

$\mathrm{H}$ in $M$. globulata, P. plicata, $P$. stoliodes
Appendix 2. Continued.

Internode Character nr. Homoplasies $(\mathrm{H})$ and reversals and state

(R)

\begin{tabular}{|c|c|c|}
\hline & & $\begin{array}{l}\text { ta, } P . \text { goniodes \& internodes } \\
73-72 \text { \& } 131-129\end{array}$ \\
\hline & \multicolumn{2}{|l|}{$32-3$} \\
\hline & $47-4$ & $\mathbf{H}$ in $C$. immaculata \\
\hline & $65-2$ & $\mathrm{H}$ in internode $131-129$ \\
\hline & $120-2$ & $\mathrm{H}$ in internode $104-103$ \\
\hline \multirow[t]{3}{*}{ 93-88 } & $95-3$ & \\
\hline & $110-2$ & $\mathrm{H}$ in $A$. latifrons \\
\hline & $135-2$ & \\
\hline 92-91 & $6-2$ & $\begin{array}{l}\mathrm{H} \text { in } V . \text { superba \& internode } \\
138-137\end{array}$ \\
\hline $93-92$ & $101-2$ & $\mathbf{R}$ in $G$. pennyi \\
\hline $111-93$ & $144-2$ & \\
\hline $96-94$ & $45-2$ & $\mathbf{H}$ in $G$. chinai, $P$. dioedes \\
\hline \multirow[t]{2}{*}{$103-96$} & $94-2$ & \\
\hline & $104-2$ & \\
\hline \multirow[t]{3}{*}{ 99-97 } & $52-1$ & $\begin{array}{l}\text { H in } M . \text { globulata \& inter- } \\
\text { node } 86-81\end{array}$ \\
\hline & $70-2$ & \\
\hline & $75-4$ & $\mathrm{H}$ in internode $13-12$ \\
\hline 99-98 & $120-4$ & $\begin{array}{l}\text { H in } A . \text { hastulata, } G . \\
\text { varicolor \& internode } 69-62\end{array}$ \\
\hline 100-99 & $105-2$ & $\mathbf{R}$ in $\boldsymbol{P}$. plicata \\
\hline $102-101$ & $131-3$ & $\mathrm{H}$ in internode $129-124$ \\
\hline \multirow[t]{2}{*}{$104-103$} & $88-2$ & $\mathrm{H}$ in internode $59-58$ \\
\hline & $120-2$ & $\mathrm{H}$ in internode $86-85$ \\
\hline $109-104$ & $88-2$ & $\begin{array}{l}\mathrm{H} \text { in internode } 59-58 \\
\mathrm{R} \text { in } P \text {. bidigitula, } P \text {. nana, } P \text {. } \\
\text { woodlarkensis }\end{array}$ \\
\hline $108-107$ & $111-2$ & \\
\hline $110-109$ & $21-3$ & $\begin{array}{l}\mathrm{R} \text { in } P \text {. bidigitula, } P \text {. nana, } P \text {. } \\
\text { woodlarkensis }\end{array}$ \\
\hline $112-111$ & $49-6$ & $\begin{array}{l}\mathbf{R} \text { in several species of Papua- } \\
\text { psaltria }\end{array}$ \\
\hline \multirow[t]{3}{*}{$140-112$} & $16-1$ & $\mathrm{H}$ in $M$. toxopeusi \\
\hline & $20-1$ & $\begin{array}{l}\mathrm{H} \text { in Aedeastria, } M . \text { viridica- } \\
t a, T . \text { sarissa }\end{array}$ \\
\hline & $28-3$ & $\begin{array}{l}\mathrm{R} \text { in } G \text {. stylata, O. insignis, } \\
\text { many Papuapsaltria species } \\
\text { further evolved? in internode } \\
60-57 . \mathrm{H} \text { in } M \text { Mda }\end{array}$ \\
\hline \multirow[t]{3}{*}{$114-113$} & $71-3$ & $\mathrm{H}$ in $A$. cheesmanae \\
\hline & $134-2$ & \\
\hline & $149-2$ & \\
\hline $123-118$ & $125-2$ & $\begin{array}{l}\mathrm{R} \text { in } A . \text { hastulata } \\
\mathrm{H} \text { in } T \text {. sicula }\end{array}$ \\
\hline $136-123$ & $17-2$ & \\
\hline $127-126$ & $129-2$ & \\
\hline $129-128$ & $\begin{array}{l}129-(2+3) \\
32-2\end{array}$ & $\begin{array}{l}\mathrm{H} \text { in } A . \text { hastulata } \\
\mathrm{H} \text { in } M . \text { inflata, } M . \text { globulata } \\
\text { \& internode } 73-72\end{array}$ \\
\hline
\end{tabular}

and state (R)


Appendix 2. Continued.

\begin{tabular}{|c|c|c|}
\hline Internode & $\begin{array}{l}\text { Character } \mathrm{nr} \text {. } \\
\text { and state }\end{array}$ & $\begin{array}{l}\text { Homoplasies (H) and reversals } \\
\text { (R) }\end{array}$ \\
\hline & & $\mathbf{R}$ in $\boldsymbol{T}$. sicula \\
\hline \multirow[t]{4}{*}{$131-129$} & $5-4$ & $\begin{array}{l}\text { H in Prasia \& internode } \\
139-138\end{array}$ \\
\hline & $30-5$ & $\begin{array}{l}H \text { in } B \text {. inconstans, } M \text {. inflata, } \\
P . \text { goniodes \& internodes } \\
73-72 \& 86-85\end{array}$ \\
\hline & $90-2$ & $\mathrm{R}$ in $T$. adipata, $T$. lanceola \\
\hline & $152-3$ & $\begin{array}{l}\text { H in G. rubricata, M. globula- } \\
t a, M u d a\end{array}$ \\
\hline $131-130$ & $17-4$ & $\begin{array}{l}H \text { in } M . \text { humilis, Prasia, inter- } \\
\text { nodes } 72-71 \& 139-138\end{array}$ \\
\hline $135-131$ & $33-3$ & \\
\hline $135-134$ & $112-2$ & \\
\hline $136-135$ & $61-2$ & $\begin{array}{l}R \text { in } M . \text { globulata, } M . \text { toxo- } \\
\text { peusi \& internode } 127-126\end{array}$ \\
\hline $139-136$ & $10-2$ & $\begin{array}{l}\mathrm{R} \text { in } A . \text { bullata, } A . \text { digitata, } A \text {. } \\
\text { dilobata, } M . \text { toxopeusi, } M . \\
\text { viridicata. } \mathrm{H} \text { in } G . \\
\text { stenocephalis }\end{array}$ \\
\hline \multirow[t]{2}{*}{$139-138$} & $5-4$ & $\begin{array}{l}H \text { in Prasia \& internode } \\
131-129\end{array}$ \\
\hline & $9-3$ & \\
\hline
\end{tabular}

Appendix 2. Continued.

\begin{tabular}{|c|c|c|}
\hline Internode & $\begin{array}{l}\text { Character nr. } \\
\text { and state }\end{array}$ & $\begin{array}{l}\text { Homoplasies (H) and reversals } \\
\text { (R) }\end{array}$ \\
\hline & $17-4$ & $\begin{array}{l}H \text { in } M \text {. humilis, Prasia, inter- } \\
\text { nodes } 72-71 \text { \& } 131-130\end{array}$ \\
\hline & $13-2$ & $\mathrm{H}$ in Prasia \\
\hline & -2 & $\mathbf{H}$ in Prasia \\
\hline & $26-$ & \\
\hline & & \\
\hline $140-139$ & $41-2$ & $\begin{array}{l}\mathrm{R} \text { in } T \text {. spelunca, } T \text {. sicula, } M \text {. } \\
\text { globulata, } C \text {. immaculata \& in- } \\
\text { ternode } 136-123\end{array}$ \\
\hline \multicolumn{3}{|c|}{$\begin{array}{l}\text { Kemarks. - Character } 41-2 \text { is } \mathrm{H} \text { in the PAUP reconstruction; } \\
\text { character } 43-3 \text { is placed at the base of Gymnotympana and } \\
\text { Venustria; character } 73-2 \text { is placed on internode } 47-40 \text { by the } \\
\text { PAUP reconstruction; character } 150-1 \text {, regarded apomorphous } \\
\text { for the Bismarck species of the bloetei group, is regarded plesio- } \\
\text { morphous for that group in the PAUP reconstruction; character } \\
153-4 \text { is placed on internode } 9-8 \text { by the PAUP reconstruction, } \\
\text { presumably due to the interpretation of lacking information. }\end{array}$} \\
\hline
\end{tabular}


Appendix 3. Data matrix (? = unknown; - = structure absent; capitals represent the following polymorphies: $\mathrm{A}=1,4$; $\mathrm{B}=1,2$; $\mathrm{C}=5,6 ; \mathrm{D}=1,3 ; \mathrm{E}=3,4,5,6 ; \mathrm{F}=1,4)$

oharector nr

1 B.guttulipennis 2 B.mamorata 3 B.nesuta 4 B.intermedia 5 B.splendida - B.parva

7 B.mamillate - B.erabuensis Q B.gibberosa 10 B.bipunctata 11 E. Iaminifer 12 B.retracta 13 B.brongoremai 14 B.viridis 15 B.lorentzi 16 B. rufula 17 B.turgida 18 B.furcillate 19 B.kankarensis 20 B.conviva 21 B.Iaureli 22 B.schulzi 23 B.quadrifida 24 B.hardyt 25 B.guttulinervis 26 B.roonensis 27 B.inconstans 28 B.birol 29 B.blootel 30 B.macgillavryi 31 B.papuensis 32 B.bismarckentis 33 B.menusentis 34 B.mubsauensis 35 B.brandd 36 B.sediacokorum 37 B.roynhoudd 38 B.cristovalensis 39 B.edaubert 40 B.maddisoni 41 B.gressitti 42 B.bilebanarai 43 B.mendena 44 B.marginat 45 B.boulardi 46 B.rolumae 47 B.exhaveta 48 B.bicolorata 49 B.coloesoa 50 B.rosei 51 B.vendorhammo 52 B.wawneis 53 B.veraicolor 54 B.man 55 B.tenuispina 56 B.eilveri 57 B.davios 58 B.pigrami 50 B.hartonol 60 B.lorias 61 B.tortuini 62 B.hamilton 63 B.bemmelon 64 B.wegenert 65 S.sahebdivant" 66 S.biarda 67 S.hulbregtsa 68 G.strepilans 69 G.viridis 70 G.dah: 71 G.nbricate 72 G.stridone 73 G.obientis 74 G.ubnotitn 75 G.nigravirgula
11111111112222222222333333333344444444445555555550660606 123456700012345670001234567800123456700012345670001234567800123456 21122111111111111121111212112111112111211112111111111113211111111111

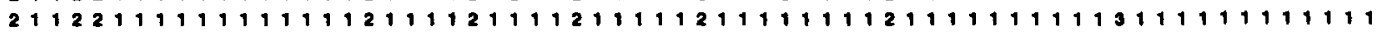

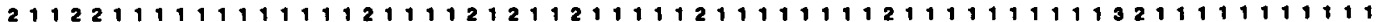

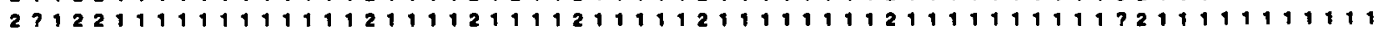

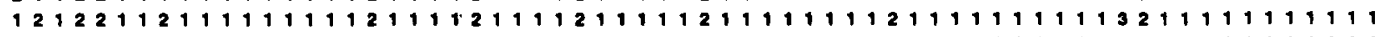

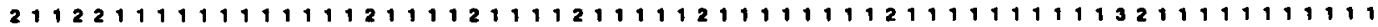

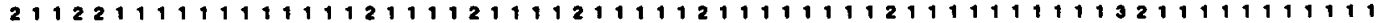

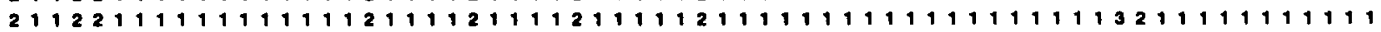

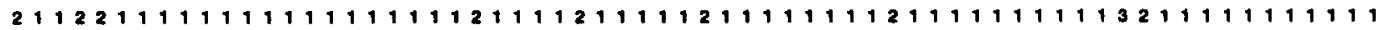

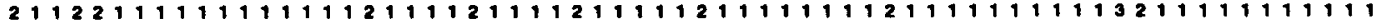

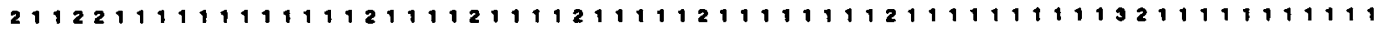

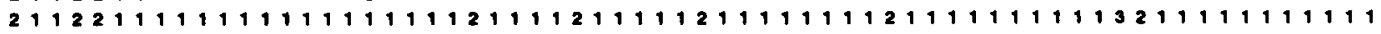

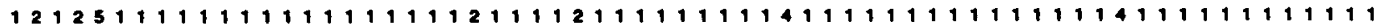
121251111111111111111112111121111111111411111111111111114111411111111

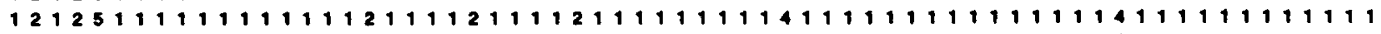

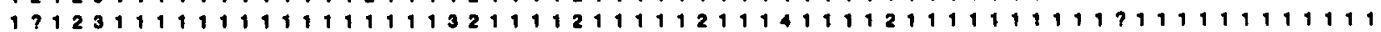

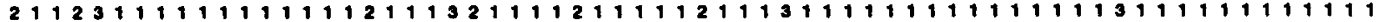

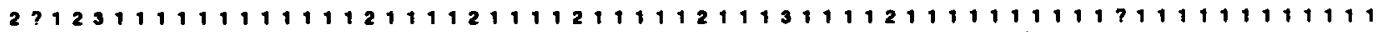

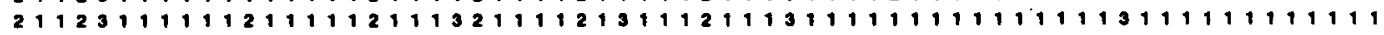

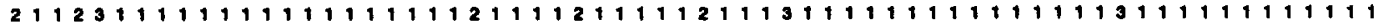

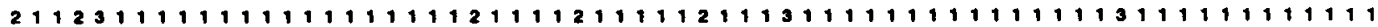

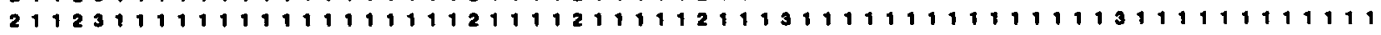

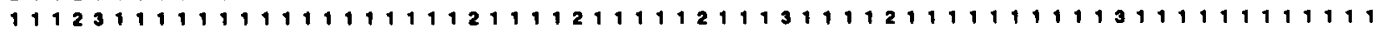

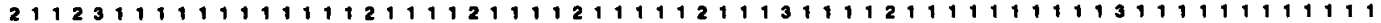

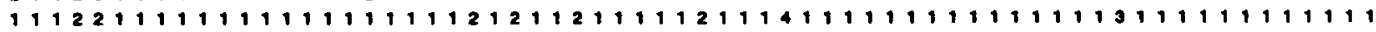

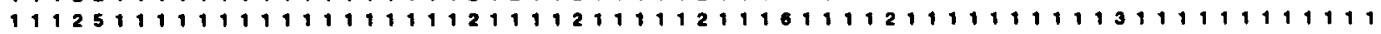

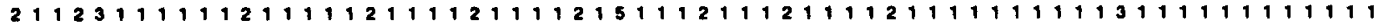

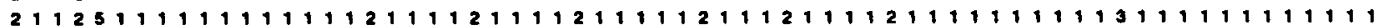

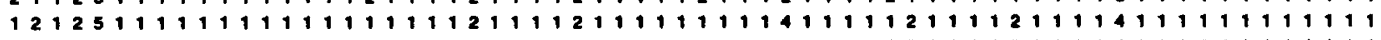
121251111111111111111121111211111111141111121111211114111111111111 121251111111111111111121111211111111441111121111211114111111111111

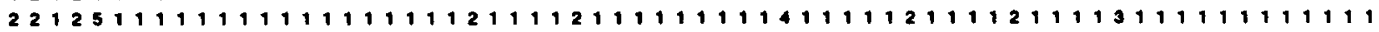

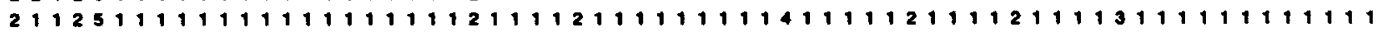

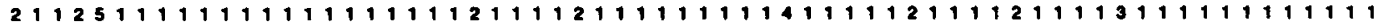

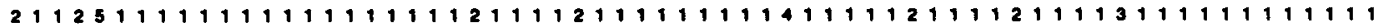

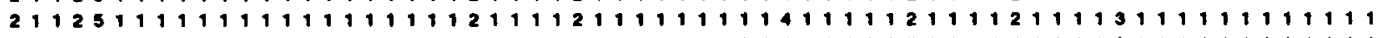

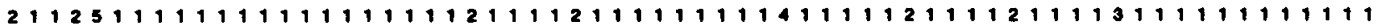

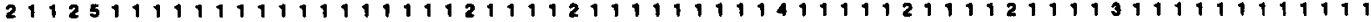

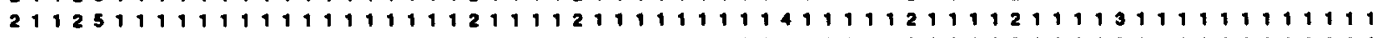

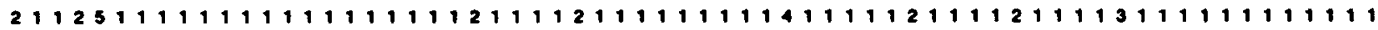

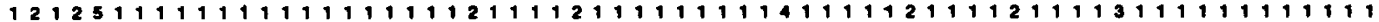

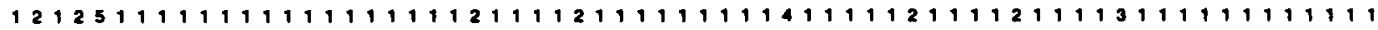
121251111111111111111121111211111111141111121111211113111111111111

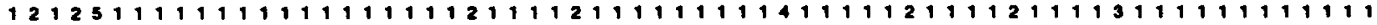

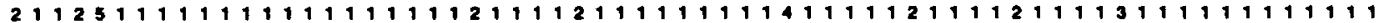

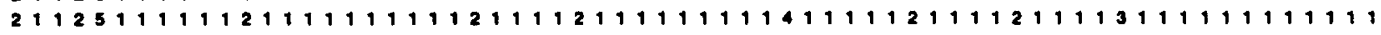

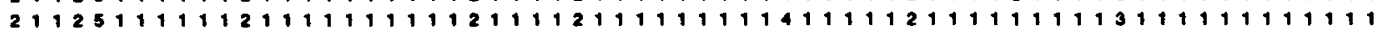

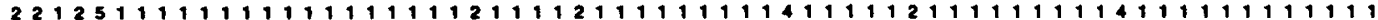

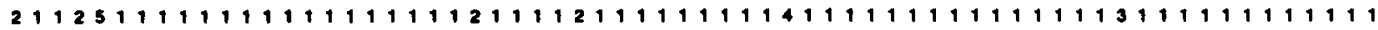

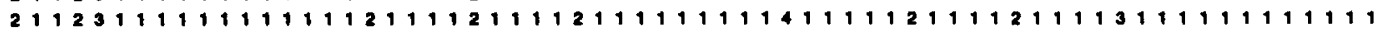

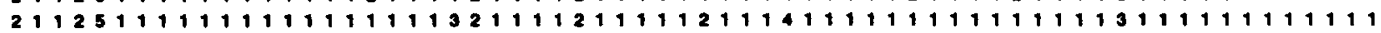
2112211111111111111113211112141112111441111211111111113111111111111 1112311111111111111113211112141112111411112111911111113111111111111

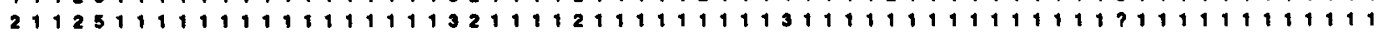

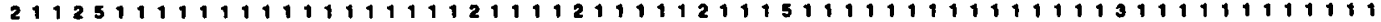
211231121111112112111121211211111192141111111411111113111111111111 211221111111111112111121111211111112131111121121511921121111111111 1112211211111121121111212112111111121441111121421511123121111111111 211251111111111111211112111121111111121411111111111111117121111111111

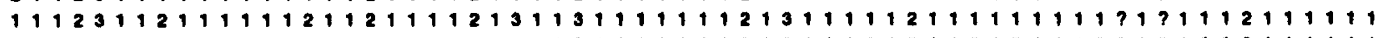
1112311211121121121111213113111111121311111121121511123121112111111 $1112211211111211121111211111211112_{2} 121411111121121311123111112111111$

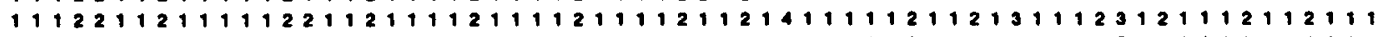

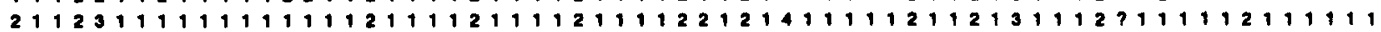
1111111211131121121121111113111111111141111111211111111121111111211

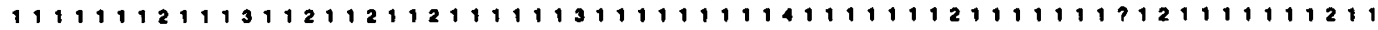

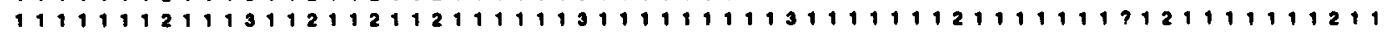
11111112112312213211211111131111111122332112121121522125121212111111

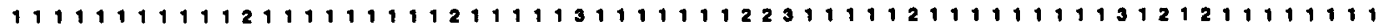

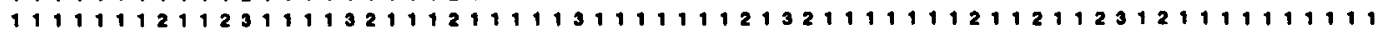

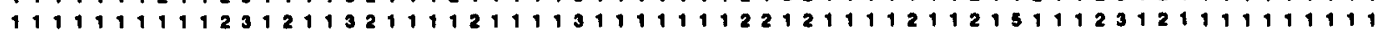
1111111211231221121121111113211111122421111121122522121221111112111 11111112112312211211211111132111111122112111211225221212211111112111 1111111211231221121121111113211111112211211121122522121221111112111 1111111211231231121121111113211111122111111121121312121121212112111 
Appendix 3. Continued.

cheracter nr

76 G.stenocepphalis 77 G.parvule 78 G.membrene 79 G.minoramembrans 60 G.phyloglycere ir G.lengorild 82 G.hireuta 3 G.olvacese 64 G.votiam B5 G.montene 86 G.nile 87 G.varicolor 8 V.apperbe 89 C.vitripennis 90 C.suthusa 91 C.ume 2 O.maignis Q3 GI.vinidis 94 G.llava - 5 G.llavede o6 G.stylata 97 G.viridula 98 G.paltida 90 G.pallidula 100 G.chine 101 G.permy 102 P.phyHophora 103 P.goniodes 104 P. angulate 105 P.lactiant 106 P.brassi 107 P.stollodes 108 P.plicata 100 P.spinigera 110 P.bidigitula 111 P.ungula 112 P.nene 113 P.woodlarkensis 114 P.ustulate 115 P.novarioe 116 P.beasi 117 P.dolabrate 118 P.toxopei 119 P.dioeder 120 A.cobrope 121 A eepia 122 A.latitrona 123 A.kaientis 124 A.waigeuneneis 125 A.digitata 126 A.hastulata 127 . A.cheosmenes 128 A.molucoensis 129 A.obionit: 130 A.butiate 131 A. Wlobets 132 T.adipatu 133 T.pnoumallea 134 T.spelunca 135 T.goboese 136 T.sicula 137 T.lanceole 138 T.sarisea $139 \mathrm{M} . v i n d i c a t e$ 140 M.globulala 141 Minconspiau 142 M.humilis 143 M.inflata 144 M.loxopeurel 145 C.echmelted 146 C. enundore: 147 Cimmacalat 148 Prasia $149 \mathrm{midh}$
11111111112222222222333333333344444444445555555555666606 123456780012345670001234567800123456700012345678001234567890123450

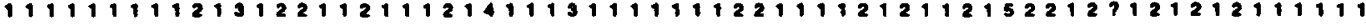

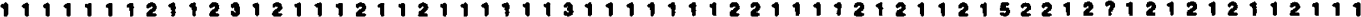

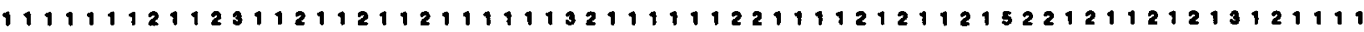
11111111111221111111112111111131111111122111912121121522121121213121111 141111121123121112112111111321111112211111121121522121121212111111 111111121123113112112111111311111112211112121121522127121212111111

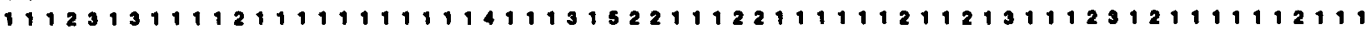

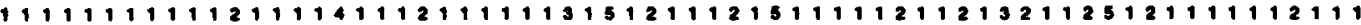

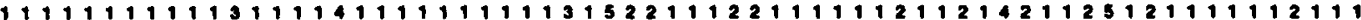

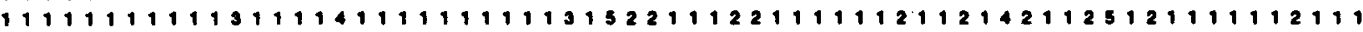

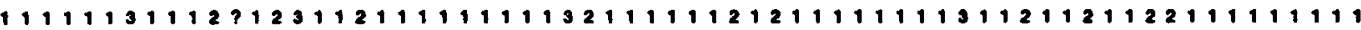

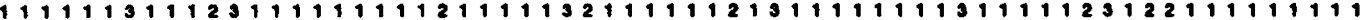

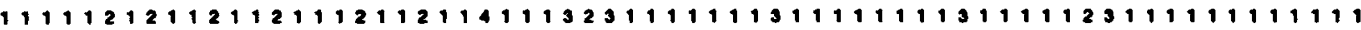

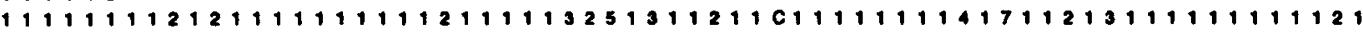
111111121121122112111211111325131124171111111341711213111111111121

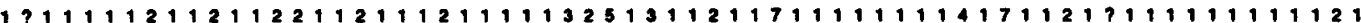

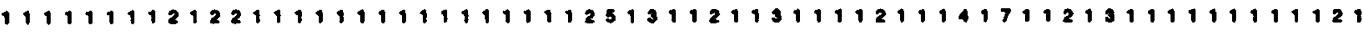

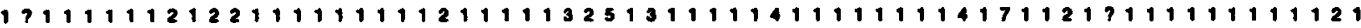

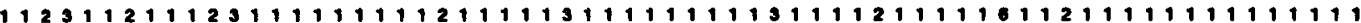

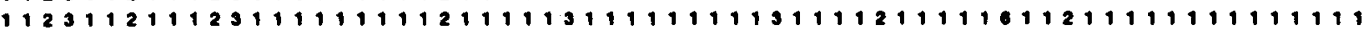

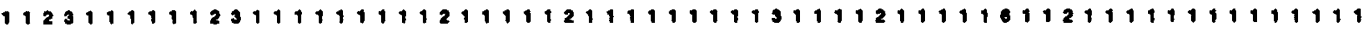

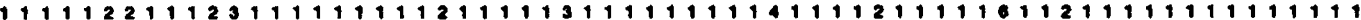

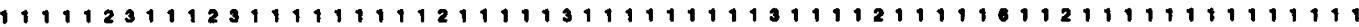

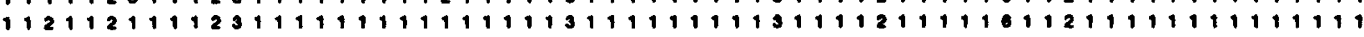
112311111111111411111211111311111111131111212111611211111111111111

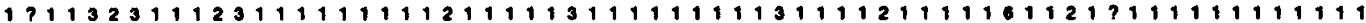

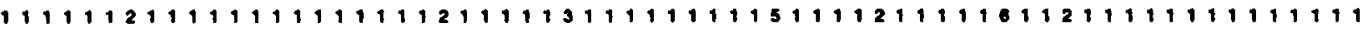

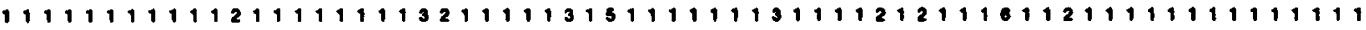

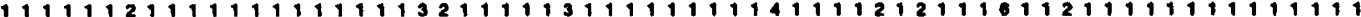

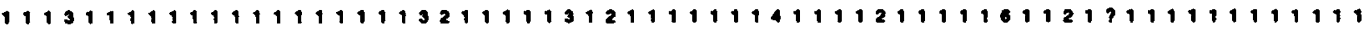

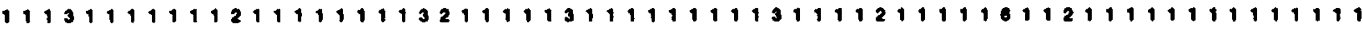

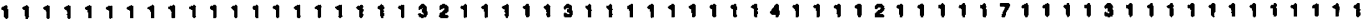

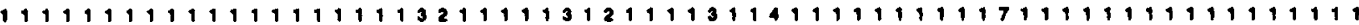

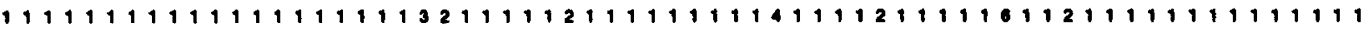

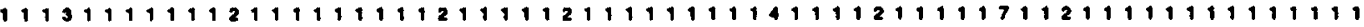

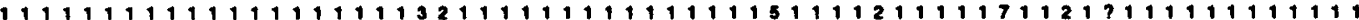

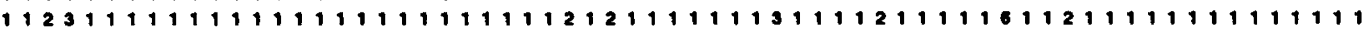

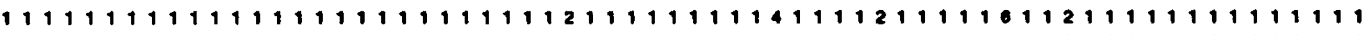

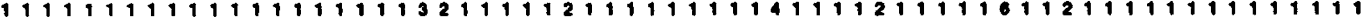

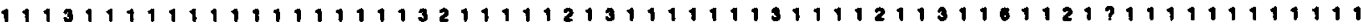

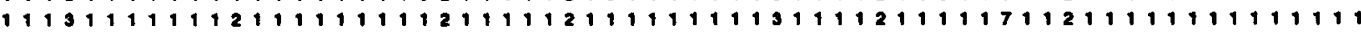

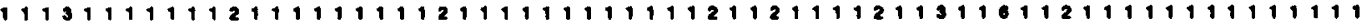

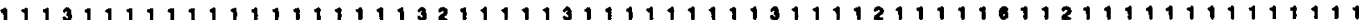

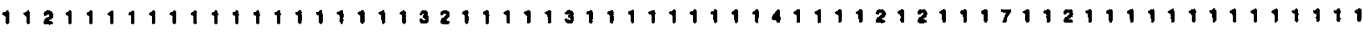

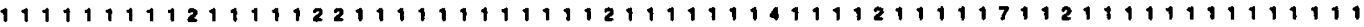

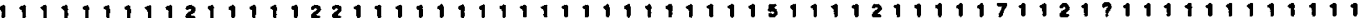

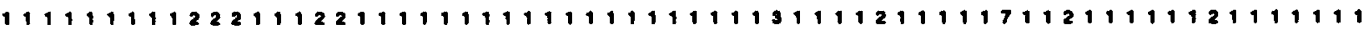

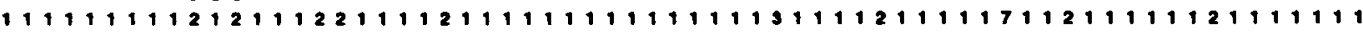

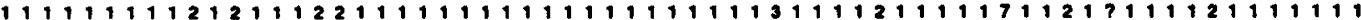
111111211112111221121211111111111111141111211111711217111111111111 112111111212111221111211111111111111121111211111711211111121111111

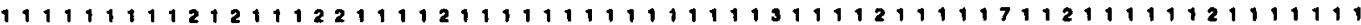

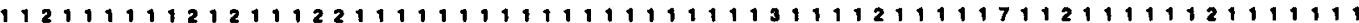
111111111212111221111111111111111111121111211111711211111111141111

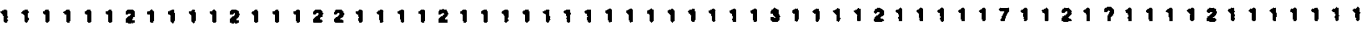

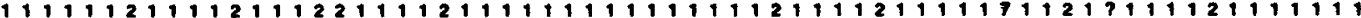
11114111221211121112111111111151131411311221211111711217111111211121 1121411122111112111212131111151130141131121211111711213111111211121

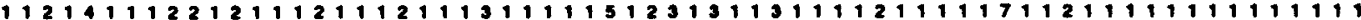
112141112212111211121213111115123131131121211111711212111111111122 112141112212111211121211111111111111141111211111711211111111111111 112141112212111211121213111145123141131421211111711211111111211122 1121411122111112111112131111151231111131121211111711211111111211122

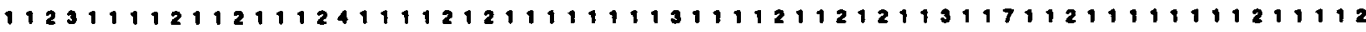

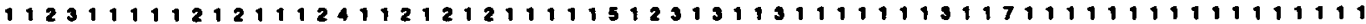

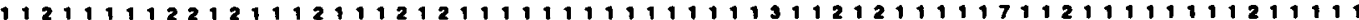

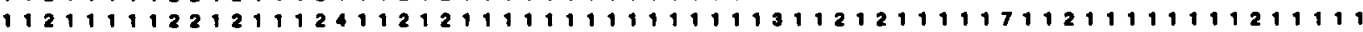

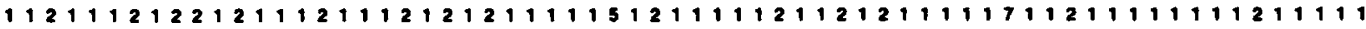

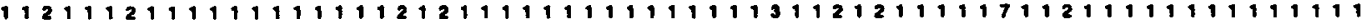
111142313111211241221212122116171141141121121311711217111114111111

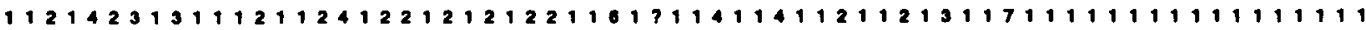

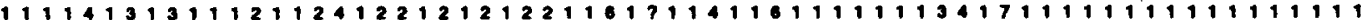

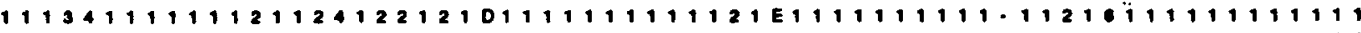

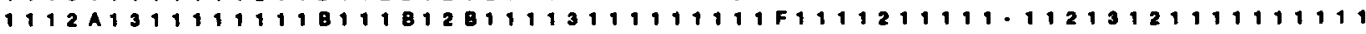


Appendix 3. Continued.

ohareater nr

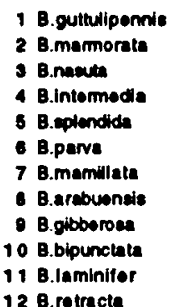

12 B.retracte

13 B.brongeremal

14 B.Wridis

15 B.Iorentz|

16 B.rufula

17 B.turgida

16 B.furcillate

10 B.kenkarenels

20 B.convive

21 B.leurell

22 B.echulat

23 B.quadrifida

24 B.hardy!

25 B.guttulinervis

26 B.rooneneis

27 B.inconetume

28 B.birol

20 8.blockl

30 B.macgillavryi

31 B.papuentis

32 B.biemarckensis

33 B.manuenesis

34 B.museacuends

35 B.brandt

36 B.eodlucokonm

37 B.roynhouds

38 B.cristovalensis

39 B.edacioert

40 B.maddiconi

41 B. grossilti

42 B.bilebenaral

43 B.mendenal

45 B.boutaret

46 B.rotumae

47 8.exheunt

48 B.bicotorate

40 B.coloenese

50 B.rosed

51 B.vandemammeni

52 B.weunneis

53 B.vernicolor

54 B.med

55 B.lenuispine

58 B.ellven

57 B.davio:

58 B.pigrami

59 B.hartonol

60 B.lorive

61 B.fortuinl

62 B.hamilioni

63 B.bemmelori

64 B.wegener

65 S.sumedivanil

66 S.biardae

- 7 S.mulbregtea

60 G.strepitane

60 G.viridia

70 G.danll

71 G.nubricate

72 G.utridene

73 G.oblendis

74 G.ectenotata

75 G. nigravirgula
11111111111111111111111111111111111111

077777777778000000000000000000000001111111111222222222233 70001234567000123450700012345678001234567000123456780012345678001

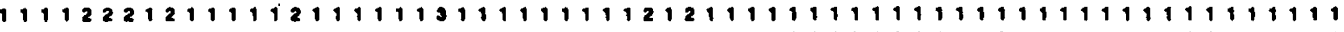

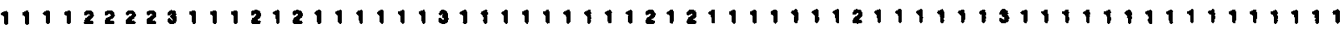

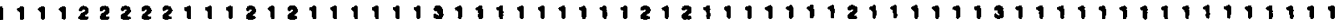

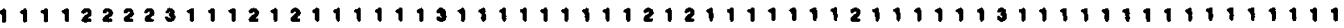
1111222231112121111113111111111121211111111111111121111111111111111

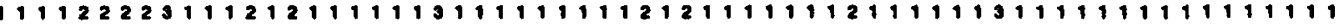

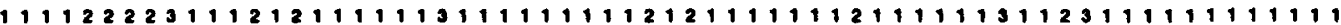
11112222311121211111131111111111212111111112111111131123111111111111

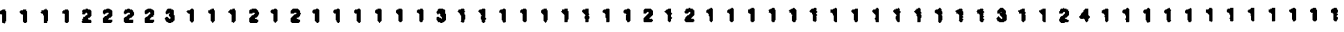

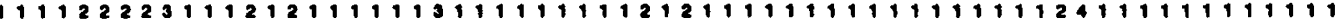

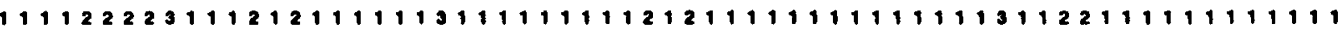
11112222311121211111131111111112121111111911111131122111111111111

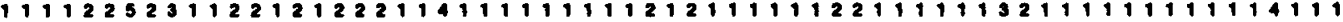

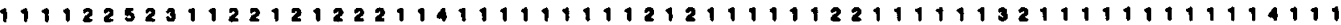
$11112252311221212221141111111112121111112 ? 11111132111111111114111$

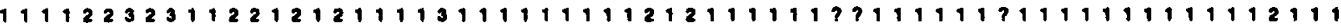

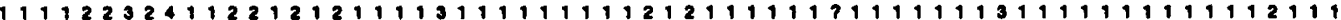

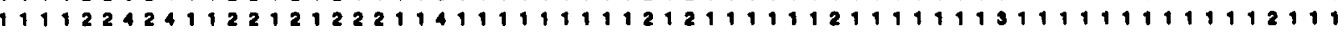

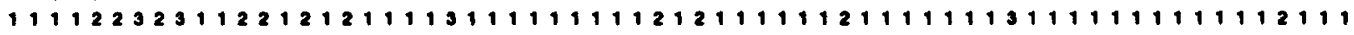

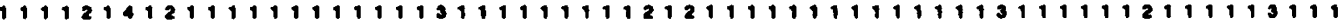

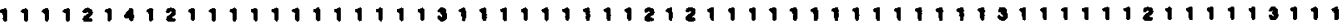

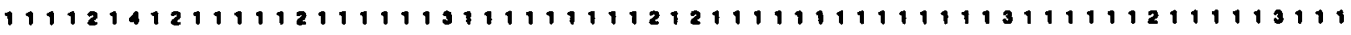

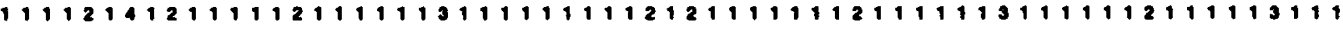

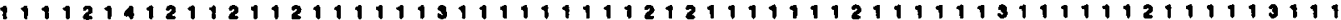

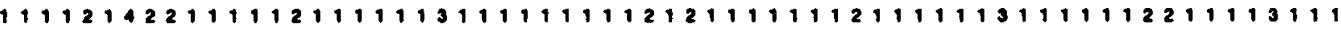

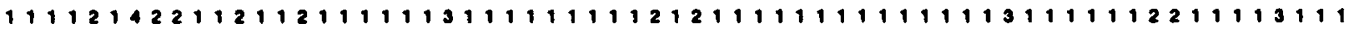

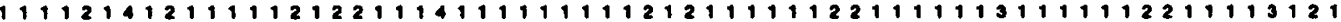

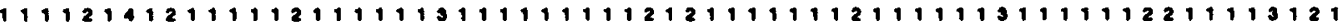
1111216121111112111113111111111112121111111121111111211111111111111111

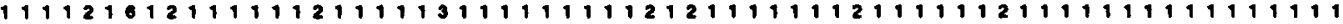

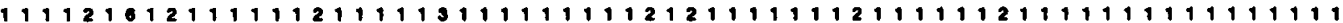

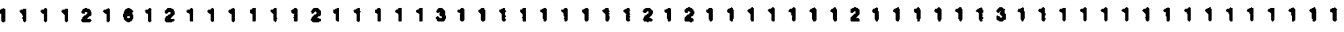
11112101211111121111131111111112121111111211111131111111111111111

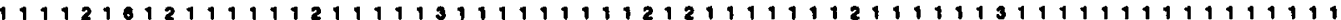
11112141211111121111131111111112121111111121111111311111111121111111

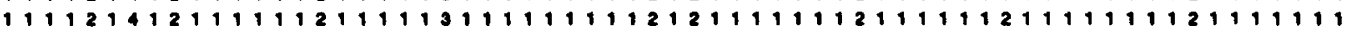

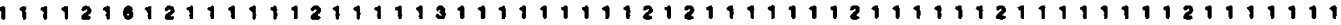

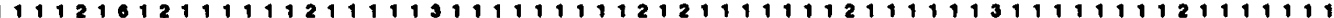

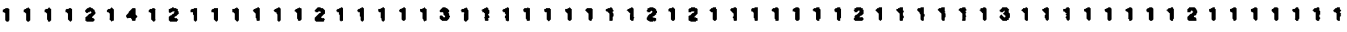

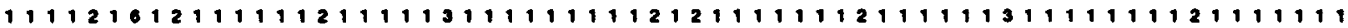

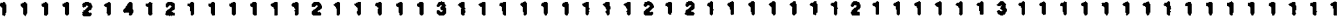
1111216121111112111113111111111112121111111112111111131111111111111111 1111210121111112111113111111111121211111112111111121111111111111111

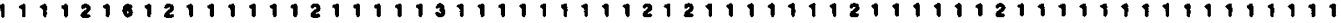

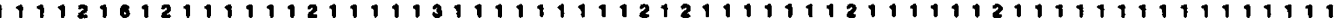

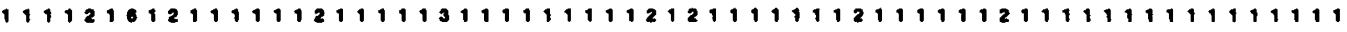
111121111111211122111123111111111112121111111121111111312111111141114111

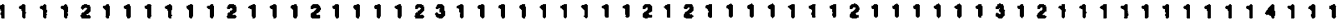

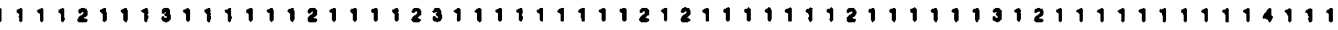

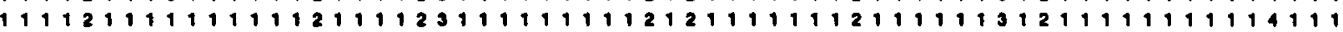

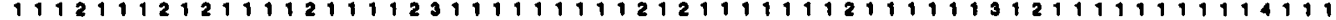

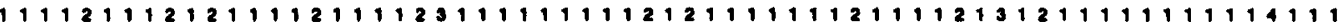

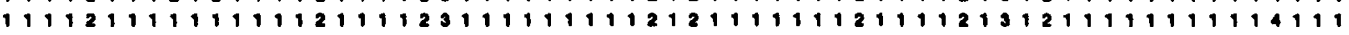

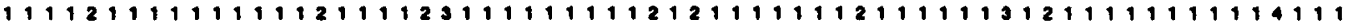

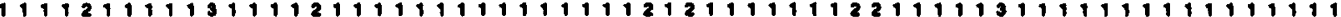

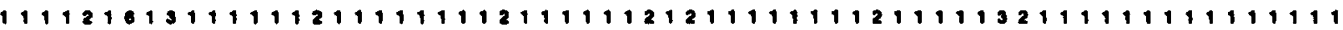

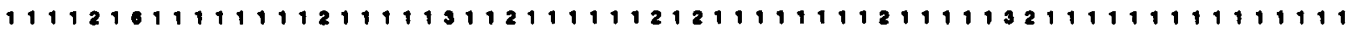

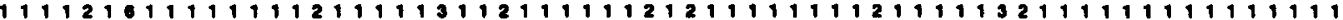
11112101111114121111131121111112121111111121111111111191111215111 11112101311111121111111121111112121111111171111111111111111215111

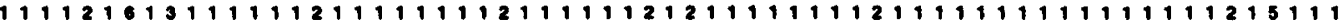

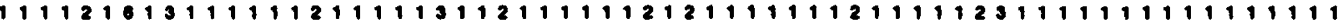

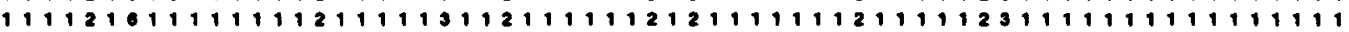

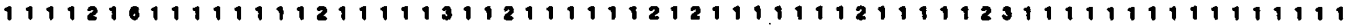

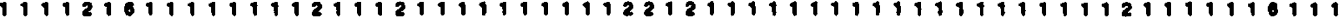

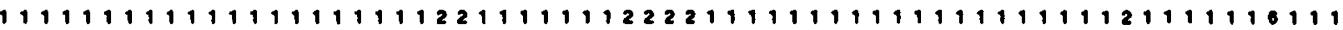
11111111111111111111121121111112221111111111111111111111121111116111

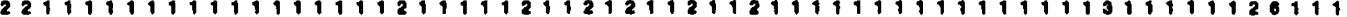

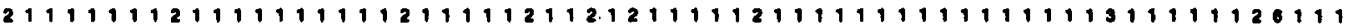

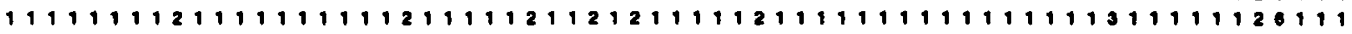

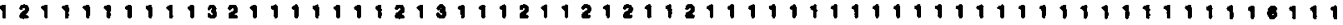
12111111111111111112112112112221111121121111111111111511111116111 22111111111111111112132122112221111121121111111111111511111116111 22111111111111111112132112112121111121121111111111111511111110111 22111111111111111112112112212121111121111111111111111411111116114 
Appendix 3. Continued.

cherweter $\mathrm{nr}$

76 G.stonocephalis 77 G.permula 78 G.membrane 70 G.minoramembrans 1 G.lengerald 82 G.hirata B 3 G.olivacas 44 G.vertami 85 G.montente 86 G.ruta 87 G.varicolor - 8 V.euperta - 9 C.vitripennis o 0 C.authea Q 1 C.tumar 92 O.inaignie - 3 GI.viridis 04 G. Rave o5 G.llaveola -6 G.shlata 07 G.viridula - G.pallida - G.pallidula 100 G.chine 101 G.penm 102 P.phyllophora 103 P.goniodes 104 P.engutete 105 P.lachlant 106 P.brass 107 P.stollodes 108 P.plicata 100 P.spinigera 110 P.bidigitula 111 P.ungul: 112 P.nene 113 P.woodtarkonsis 114 P.usbulate 115 P.novarias 116 P.baak 117 P.dolabrala 110 P.toxopel 110 P.dioeder 120 A.cobrope 121 A sepia 122 A.latifrons 123 A.kaiendis 124 A.waigeueneis 125 A.digitala 126 A.hasulata 127 A.checemenes 128 A.moluccensis 120 A.obionile 130 A.bullate 131 A.dllobate 132 T.udipeta 133 T.pnoumetica 134 T.epelunct 135 T. olobcen 136 T.sicula 137 T.lenceole 138 T.sarises $138 \mathrm{M}$.vindicata 140 M.globutata 141 Minconepicus 142 M.humilis 143 M.infiata 144 M.loxopeuser 145 C.echnelty 146 C.saundereil 147 Cimmaculata 148 Pratia 140 Much

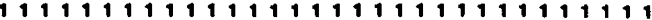
0607777777777000000000000000000000000000011111111111222222222233 70001234567800123456709012345670001234567000123450700012345670901

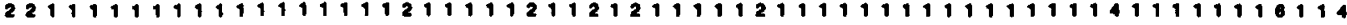

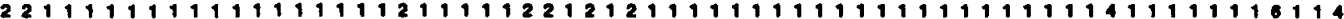
22111111111111111111111311111112111112111111111111111111311111116111

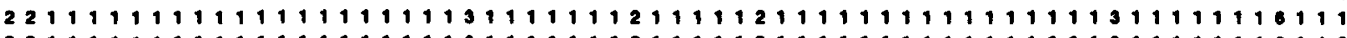

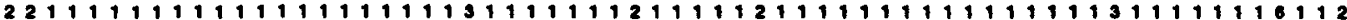

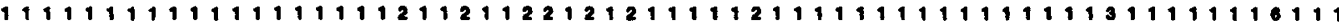

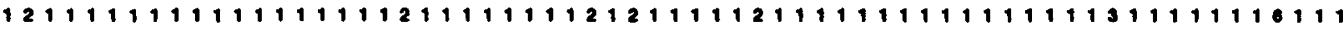
111111111111111111121111211121211111211111111111111111311111116111

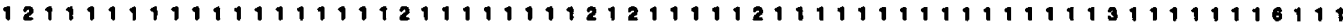
221111111111111111121111111121211111211111111111111111311111116111

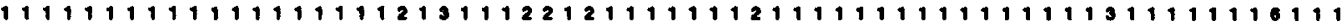

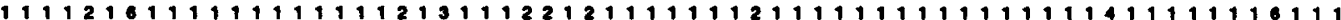

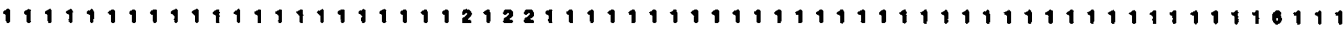

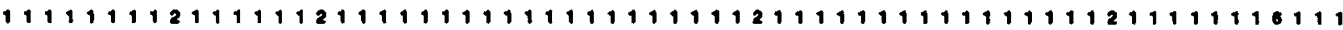

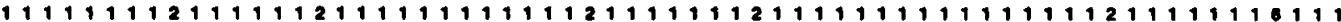

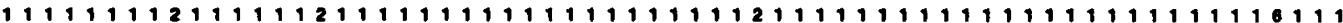
11111111311111121111111111111111111121111111111111111211111116111 11211111211111121111111111111111111111111111111111111211111116111

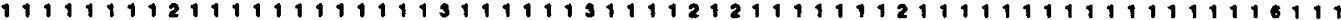

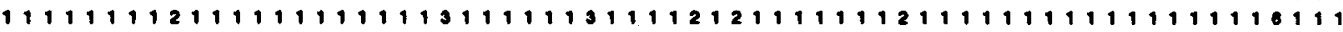

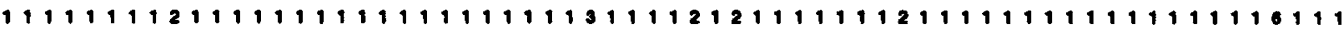

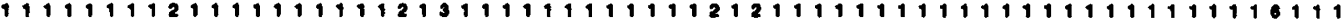

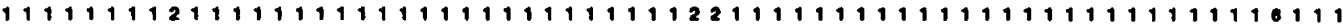

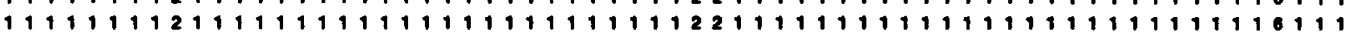

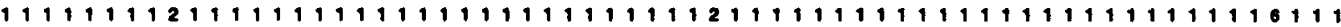

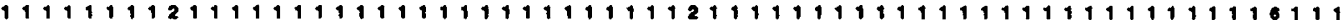

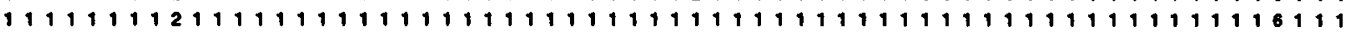
111111112111111111111221111211111111221111111111111111211111116111

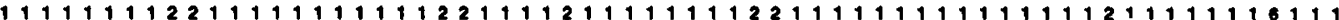

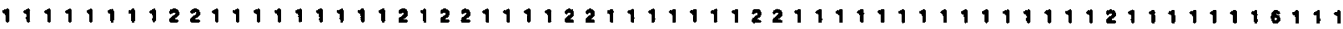
111111112111111111111221111211111111221111111111111111211111116111 111222114111111111111211111111111111212111111111111111211111116113 1112221141111111111112111111211111112111111111111111111211111110113

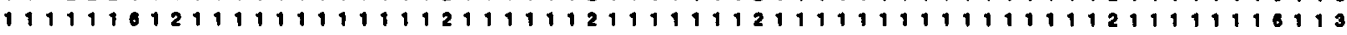

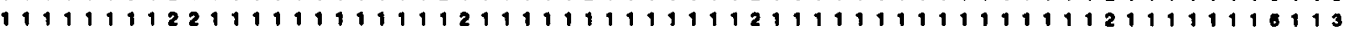

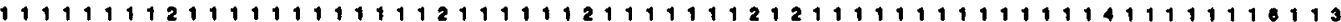
11111111211111111111111111112111111121211111111111111411111116113

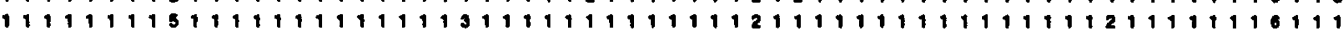

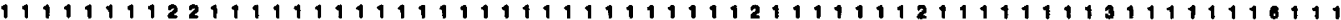
$11+111112211111111111111111111111111111111111211111111111111110111$

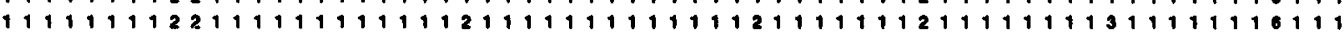

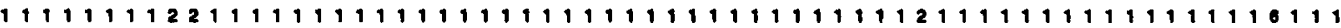

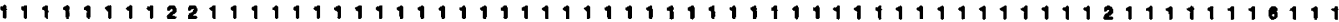

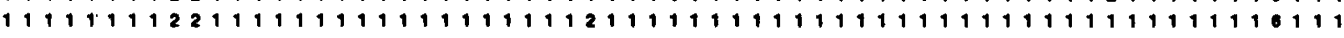

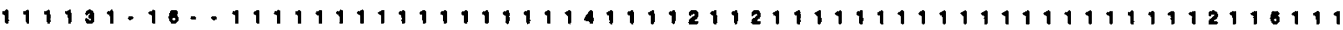

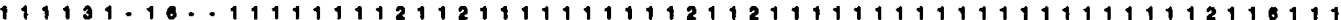
11111111211111111112111111112111121111111112111111111111112116111

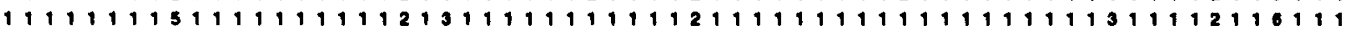

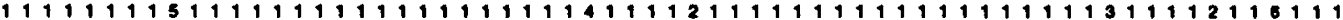
14112241211111111111142112112111121111111111111111111111112110111

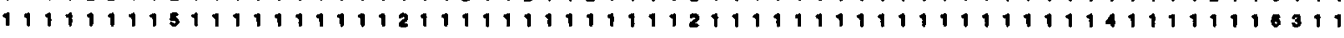

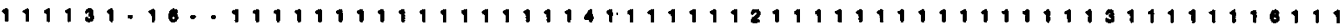

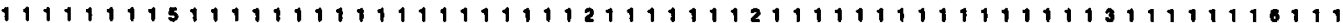

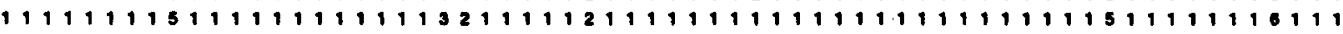

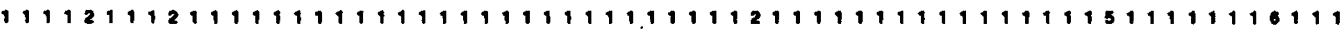

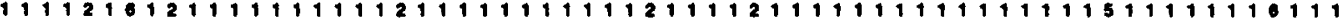
11111111211111121111111111111111111121111111111111111511111116113 11111111311111121111111211111111111121111111111111111511111116113

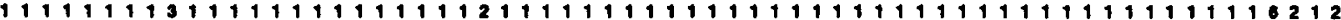
1111111121111111111111121111111112111111111111111111111111111116212

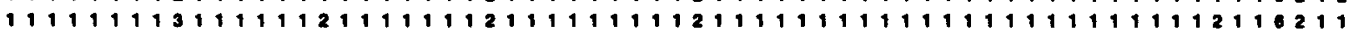

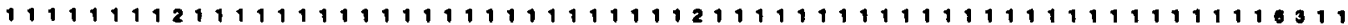

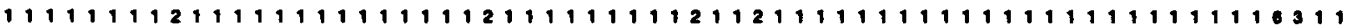

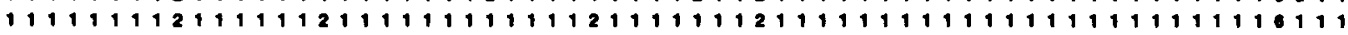

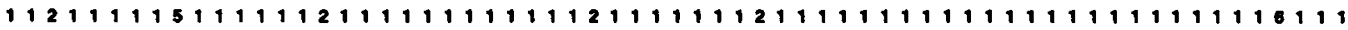

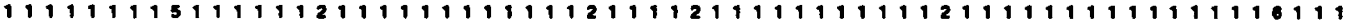

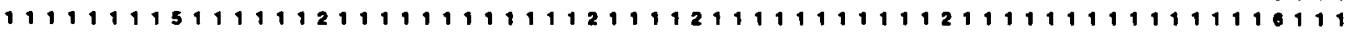

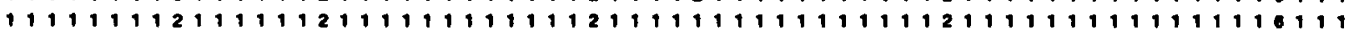

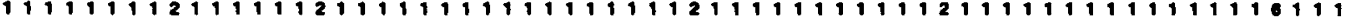

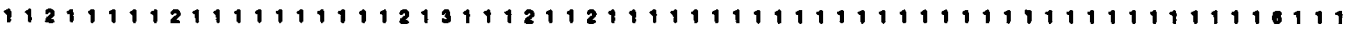

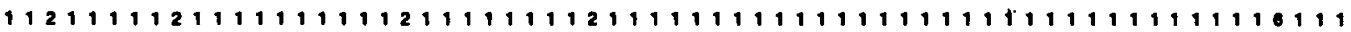

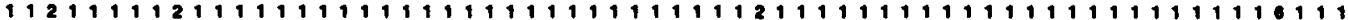

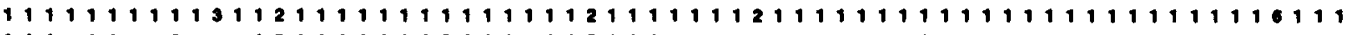
$111 \ldots 11 \ldots \ldots \ldots 12111,1113111,112111 \ldots \ldots \ldots \ldots$ 
Appendix 3. Continued.

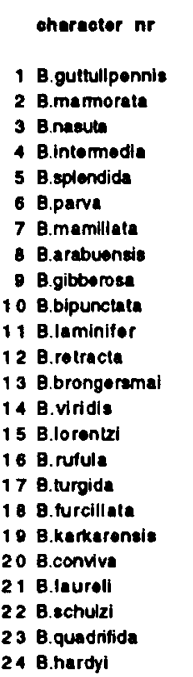

25 B.gultulinervis

26 B.roonensis

27 Binconstane

28 B.birol

29 B.bloetol

30 B.macgillavryi

31 B.papuensis

32 B.bismarckensis

33 B.manusensis

34 Bmussaueneis

35 B.brandit

36 B.sodlacokonm

37 B.reynhoudt

38 B.cristovalensis

39 B.edacibert

40 B.maddison

41 B.gressitti

42 B.bilebenara:

43 B.mendanal

44 B.merginate

45 B.boulardi

46 B.rotumas

47 B.exhausta

48 B.bicolorate

49 B.colosene

50 B.rossi

51 B.vandemammeri

52 B.waunsis

53 B.versicolor

54 B.mad

55 B.conuispina

56 B.sllveri

57 B.davios

5 B B.pigram

59 B.hartonol

60 B.lorieo

61 B.fortuint

62 B.hamilton

63 B.bemmelent

64 B.wegener

65 S.sahobdivan"

66 S.biarda

67 S.hubrogtseo

68 G. strepitans

60 G.viridis

70 G.dahli

71 G. nubricate

72 G.siridone

73 G.obiendis

74 G.subnotatio

75 G.nigravirgula
111111111111111111111111 33333333444444444455555 23456780012345678901234 11112111122121111111111221 $11112111121211 ? 111111441$ 11112111121211211111111 $11112111121211111111 ? ? 1$ 111121111212111111111141 11112111121211211111111 1111211112121121111114 11112111121211211111161 11112111121211211111131 11112111121211111111111441 1111211112121111111111144 111121111212111111111141 111121111112111111112111 111121111112111111122121 11112111111122111111111211 $11112111111211221111 ? ? 1$ 111121112112211121111151 $11112111211211121111 ? ? 1$ 11112111211211121111121 $1111221211121,121,11131$ 11112212111211121111131 $1111221 ? 111211121111131$ 1112211111211111111131 11112111111211111111111131 11112112111211111111111 11112111111211111111111 11112111111211121111111 11112112111211111111111 1111121111111121111111122111 111121111112111111111111 11112111111211121112111

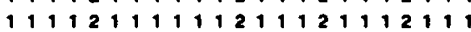
11112111111121111111112111 11112111111121111111112121 11112111111211111122121 1111211111122111111122111 111121111111211111122121 1111211111121111112212 1111211111112111111122141 11112111111211111112212 1111211111121111112212 11112111111211111122121 111121111111121111111112212121 11112111111211111122121 11112211111111211111111222121 1111211111122111111122121 11112111111122111111111111111 111121111112111111111111 11112111111211111111111 1111211111121111111111111 1111211111121111111111 11112111111121122111111111 111112111111112111111111111111 $11112111191211111111 ? ?$ 1111211111121121111111 11112112111221111111111 $11112112111211111111 ? ? 1$ 11112112111211111111111 11113112111211211111771 $111131121212111111111 ? ?$ 1111311212121111111112111 11112112111211111112111 11112111211112111111111211 , $11112112111211111412 ? ? 1$ 111111211111111113154211 $11111121111111113154 ?$ ? $111111211111111113154 ?$ ? 11111111111111121215411 11111111111112212154121 11111111111111212154111 111111111111111212154311 1111111111311111315411 11111111113112113154111 11111111111171121113153221 1111111111111111113154121

oharactor $\mathrm{nr}$

11111111191111111111111 33333333444444444455555 23456700012345670001234

76 G.stenocephals

77 G.parnula

78 G.membran 00 G.phyloglycora

Q 1 G.langerak

02 G.hirsuta

- 3 G.olivacea

84 G.vertaani

o5 G.monian

66 G.ruta

87 G.varicolor

88 V.superta

89 C.vitripennis

90 C.sutfusa

Q 1 C.rumar

82 O.insignis

23 Gl.viridis

04 G.flava

05 G.naveola

96 G.silati

97 G.viridula

90 G.pallida

99 G.pallidula

100 G.chinal

101 G.ponny

102 P.phyllophore

103 P.goniodos

104 P.angulat

105 P.lachlant

106 P.brasal

107 P.stoliodes

108 P.plicata

100 P.spinigera

110 P.bidigitula

111 P.ungula

112 P.nana

113 P.woodlankonais

114 P.uctulata

115 P.novariso

116 P.baas:

117 P.dolabrate

118 P.loxopw

110 P.diodes

120 A.cobrope

121 A.sepia

122 A.latifrone

123 A.kaiende

124 A.waigeuensis

125 A.digitala

126 A.hasulate

127 A.chosemenes

12. A.moluccentis

129 A.obioneis

130 A.buliate

131 A.dilobats

132 T.edipate

133 T.pnoumatica

134 T.spetunca

135 T.globoce

136 T.sicula

137 T.lanceola

138 T.earissa

$130 \mathrm{M}$.viridicate

140 M.globulata

141 M.inconspious

142 M.humilis

143 M.innata

144 M.toxopevel

145 C.schmeltzi

146 C.eaundorall

147 C.mmeadate

146 Prasia

149 Mude
$111111+1113112113154111$ 11111111113112113154111 11111111111312113144111 11111111111311113144111 11111111111311113144111 11111111111311113144111 11111111111111131113154112 11111111111111111133144111 11111111111111213154112 121111111111144113154211 121111111111111111111131553111 12111111111111113153 ? 11111111111111111111131533141 1111111111111111113154 ? 11121111111121113153121 111211111111121113153121 111211111111211113154121 111111111111111112111130153121 11111111111111211113153111 111111111111121113153111 11111111111122113134121 $11111111411121113153 ?$ ? $1111111111111111211 \cdot 154121$ 1111111111111112113153111 1111111111111121113154121 111111111111111113154 ? 111111111111112113154121 11111111111111131113154121 1111111111111211315412 ? 11111111111111113154121 11111111111112113154121 $11111111111112113154 ? ?$ 1111111111111211315411 11111111111112113154121 11111111111112113154111 $11111111111112113153 ?$ ? 11111111111111122113154111 11111111111111121113153111 11111111111112113154111 11111111111111111113154121 11211111111111111111113253111

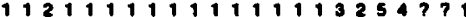
11111111111113113154121 $1111111111111211315 \% 121$ $11111111111112113144 ? ? 1$ $1111111111111111131113154 ? ? 1$ $1111111111111121131541 ? 1$ 11111111111112113154211 1411111111111112113154211 111111111111121193144111 $11111111111113113151 ? ? 1$ 11111111111113213153 ? 1 111111111111111113154 ? 11111111111113113154221 1111111111121132113134221

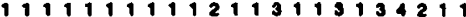
11111111112113113134221 11111111111112113154211 111111111111133113154221 11111111111112113154121 1111111111111,113154321 11111111111111113154121 11111111111111113154121 11111111111112113154121 $11111111111111111315 \% 121$ 111111111111111113154 ? 11111111111113113154121 111111111111111131113153121 $2111 \cdot \cdot 111111111111111 \cdot 153121$ $2111 \cdot 11111111111 \cdot 1543 \cdot 1$ 